Dados - Revista de Ciências Sociais

ISSN: 0011-5258

dados@iesp.uerj.br

Universidade do Estado do Rio de Janeiro

Brasil

Kaufman, Robert R.; Segura-Ubiergo, Alex

Globalization, domestic politics and social spending in Latin America: a time-series cross-section analysis, 1973-1997

Dados - Revista de Ciências Sociais, vol. 44, núm. 3, 2001, pp. 435-479

Universidade do Estado do Rio de Janeiro

Rio de Janeiro, Brasil

Disponível em: http://www.redalyc.org/articulo.oa?id=21844301

- Como citar este artigo

- Número completo

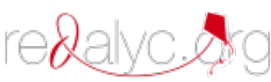

Mais artigos

Home da revista no Redalyc

Sistema de Informação Científica

Rede de Revistas Científicas da América Latina, Caribe , Espanha e Portugal

Projeto acadêmico sem fins lucrativos desenvolvido no âmbito da iniciativa Acesso Aberto 


\title{
Globalização, Política Interna e Gasto Social na América Latina: Uma Análise de Corte Transversal com Série Temporal, 1973-1997*
}

\author{
Robert R. Kaufman
}

Alex Segura-Ubiergo

\section{INTRODUÇÃO}

“Terá a globalização ido longe demais?”. Há um século que esta pergunta, título de um livro de Dani Rodrik (1997), vem sendo feita na América Latina. As questões que ela levanta, porém, ganharam força especial nos últimos 25 anos, à medida que economias, antes fechadas, de substituição de importações foram transformadas por reformas estruturais que estabeleceram vínculos muito mais estreitos entre elas e os mercados internacionais de produtos e capitais. Como em outras partes do mundo, os efeitos específicos dessa transformação nas sociedades latino-americanas ainda não estão claros. Apesar dis-

\footnotetext{
*Versões anteriores deste trabalho foram apresentadas em seminários realizados no Instituto de Estudos Latino-Americanos da Universidade de Columbia; no Departamento de Ciência Política do Massachusetts Institute of Technology - MIT; no Woodrow Wilson Center for Scholars; na reunião anual da Associação Brasileira de Ciência Política - ABCP. Os autores agradecem os comentários e sugestões de Colin Bradford, David Brown, Christian Ewig, Carol Graham, Stephan Haggard, Jonathan Katz, Daniel Kelemen, Chapell Lawson, Richard Locke, Ed Mansfield, Helen Milner, Joan Nelson, Jonathan Rodden, Nita Rudra, Robert Shapiro, Arturo Sotomayor, Alfred Stepan, Judith Tendler e Joseph Tulchin. [A tradução do original em inglês "Globalization, Domestic Politics and Social Spending in Latin America: A Time-Series Cross-Section Analysis, 1973-1997" é de Paulo Garchet.]
}

DADOS - Revista de Ciências Sociais, Rio de Janeiro, Vol. 44, nº 3, 2001, pp. 435 a 479. 
so, parece bastante nítido que ela implicou importantes modificações no equilíbrio de forças políticas e alterou as margens das opções disponíveis para os governos nacionais.

Neste trabalho, examinamos um dos aspectos mais controvertidos dessa abertura econômica: seu impacto nos comprometimentos fiscais dos governos com a seguridade social, a saúde e a educação. Muitos argumentam que a nova era de reformas neoliberais solapou as débeis proteções que os Estados da região davam a, pelo menos, alguns de seus cidadãos durante os períodos anteriores de substituição de importações. Seja isto verdade ou não, o principal desafio está em saber se os sistemas de bem-estar prejudicados podem ser reconstruídos e ampliados de forma a proteger os cidadãos expostos às novas forças de mercado, permitindo-lhes, ao mesmo tempo, competir efetivamente na nova era da "globalização".

Exploramos essas questões através de uma análise de corte transversal com série temporal das alterações nas transferências da seguridade social e nos gastos com saúde e educação em quatorze países latino-americanos, entre 1973 e 1997. São eles: Argentina, Bolívia, Brasil, Chile, Costa Rica, República Dominicana, Equador, El Salvador, Guatemala, México, Paraguai, Peru, Uruguai e Venezuela ${ }^{1}$.

Examinamos três conjuntos de questões. No primeiro, desejamos saber se a integração nos mercados globais de fato restringiu os gastos sociais. Aqui, apoiamo-nos na distinção estabelecida por Geoffrey Garrett (1999) entre uma hipótese de "eficiência", que argumenta que a crescente exposição à concorrência internacional induzirá os governos a reduzir os gastos sociais, e uma hipótese de "compensação", que enfatiza os incentivos para investimento em "capital humano" e o atendimento da demanda política por proteção contra os riscos. Nesse contexto, tratamos de verificar até que ponto tais resultados podem ser influenciados por dois conjuntos adicionais de fatores institucionais e de política interna: o do equilíbrio de poder partidário e o das pressões eleitorais das instituições democráticas.

Coerentes com as descobertas de Garrett em uma amostra global maior, mostramos que a integração comercial tem um efeito consistentemente negativo sobre o gasto social agregado, e que tal efeito é agravado pela abertura aos mercados de capitais. Esta é a mais significativa e importante descoberta de nosso estudo. Mais ainda, ao contrário 
Globalização, Política Interna e Gasto Social na América Latina...

do que se revelou em alguns estudos de países da Organização de Cooperação e de Desenvolvimento Econômicos - OCDE, os efeitos das variáveis "políticas" no gasto social agregado são fracos e inconsistentes. Nem os governos de base popular nem as democracias gastam, consistentemente, mais ou menos que governos conservadores ou regimes autocráticos.

Descobrimos, também, que a globalização e as políticas internas têm um impacto muito mais complexo quando os gastos sociais são desagregados, separando-se as transferências de seguridade social dos gastos com "capital humano", em saúde e educação. O efeito negativo da integração econômica internacional opera, primordialmente, através das transferências de seguridade social (pensões principalmente), enquanto os gastos com saúde e educação são bem menos vulneráveis. Além disso, cada tipo de gasto parece ser, também, influenciado por fatores políticos distintos: os governos de base popular tendem a proteger as pensões e outras transferências de bem-estar que beneficiam, principalmente, a classe média e os integrantes dos sindicatos, enquanto a mudança para um regime democrático tem um impacto positivo nos gastos com saúde e educação, que afetam segmentos maiores da população.

Dentre as razões que nos levam a considerar o nosso estudo original, destacamos o fato de ele apresentar medidas mais abrangentes de gasto social que aquelas encontradas nas demais amostras de países menos desenvolvidos, e que essas medidas são examinadas, em bases anuais, ao longo de um período relativamente extenso de tempo. Em nossa análise dos dados, usamos um modelo de correção de erros baseado em séries temporais combinadas, estimado através de Mínimos Quadrados Ordinários - MQOs [Ordinary Least Squares], com erros-padrão corrigidos por painel para correção da heteroscedasticidade do painel e correlação espacial, uma variável dependente defasada para modelar as dinâmicas temporais e corrigir a correlação serial; e simulações de países e tempos para controle dos efeitos fixos. Comparado a modelos de Mínimos Quadrados Generalizados - MQGs [Generalized Least Squares] e de Probabilidade Máxima [Maximum Likelihood], nosso procedimento metodológico estabelece um patamar alto para a estimativa dos níveis convencionais de relevância (Beck e Katz, 1995; 1996). Tal estimativa é mais confiável, no sentido de que estima os erros-padrão com mais eficiência e maior consistência. 
Nas seções seguintes, apresentamos nossas análises. Na primeira, esboçamos os principais argumentos teóricos sobre como a globalização e as políticas internas podem influenciar os gastos sociais na América Latina. Na segunda, discutimos as variáveis e o modelo usado na análise. Na terceira seção, apresentamos nossas descobertas sobre as mudanças no gasto social agregado. Na quarta, mostramos o impacto das variáveis políticas e econômicas, quando o gasto é desagregado, com as transferências, de um lado, e os gastos com saúde e educação, do outro. Na última, as conclusões.

\section{O ARGUMENTO: GLOBALIZAÇÃO, POLÍTICAS INTERNAS E GASTO SOCIAL NA AMÉRICA LATINA}

\section{As Hipóteses de "Eficiência" e de "Compensação"}

Essas hipóteses conflitantes sobre os efeitos da globalização no gasto social constituem um ponto de partida. Como observou Garrett (1999), há dois conjuntos bastante contraditórios de argumentos que não podem ser resolvidos sem pesquisa empírica. Cada um apresenta propostas bem distintas sobre os interesses e recursos do capital e da mão-de-obra, e sobre as opções econômicas e políticas postas aos governos.

A "hipótese da eficiência" baseia-se na premissa de que altos níveis de gasto social reduzem a competitividade nos mercados globais. Esse efeito operaria através de vários canais. Os aumentos do gasto social, por exemplo, podem estar ligados a impostos mais altos sobre as folhas de pagamento os quais aumentam o custo da mão-de-obra e reduzem a competitividade, tanto das exportações quanto dos produtos expostos, no mercado interno, à concorrência dos importados. Aumentos nos gastos fiscais podem, também, solapar a competitividade, provocando uma elevação nas taxas de juros, impedindo o investimento privado e aumentando o valor da taxa real de câmbio. À medida que os grupos empresariais ficam cada vez mais expostos à concorrência internacional é de se esperar que pressionem os governos para reduzir os gastos sociais. A integração com os mercados de capitais presumivelmente agravaria essa pressão, já que aumenta as oportunidades de saída à disposição dos detentores de ativos.

Ao mesmo tempo, podemos, também, esperar um declínio na capacidade da mão-de-obra em resistir às reduções no gasto social. É verda- 
Globalização, Política Interna e Gasto Social na América Latina...

de que o teorema de Hecksher-Ohlin pode ser interpretado de forma oposta: nos países menos desenvolvidos, de mão-de-obra abundante, a expansão do comércio levaria a um aumento nos ganhos da força de trabalho e a um maior poder de barganha perante o capital (Rogowski, 1989). Por várias razões, contudo, isso não se tem verificado na América Latina. Primeiro, como argumenta Rodrik (1997:46), falando dos países menos desenvolvidos em geral, os capitalistas têm maiores oportunidades de saída que os trabalhadores e ficam, assim, em melhor posição para fechar ou reposicionar suas fábricas diante de aumentos do custo da mão-de-obra. Mais ainda, contra as expectativas teóricas, a liberalização do comércio contribuiu, em muitas partes da América Latina, para aumentar a demanda de mão-de-obra qualificada, e não a de trabalhadores não qualificados (Stallings e Peres, 2000). Mesmo onde isso não ocorreu, a grande reserva de trabalhadores na agricultura e no setor informal cria uma folga no mercado de trabalho que não pode ser eliminada rapidamente (Rudra, no prelo). Finalmente, os sindicatos latino-americanos têm se baseado no setor público e nas indústrias de substituição de importações, ambos seriamente enfraquecidos pela liberalização do comércio. À medida que suas economias ficam mais expostas à concorrência internacional, portanto, os incentivos para que os governos reduzam o gasto social se tornam cada vez mais fortes, enquanto declinam os custos políticos de tal atitude.

A "hipótese da compensação" aponta para o efeito exatamente oposto. Ela enfoca o papel do Estado como mecanismo de compensação dos custos sociais da integração internacional e de contribuição para o desenvolvimento do "capital humano". Nos países da OCDE, essa hipótese é confirmada por diversos estudos que revelam uma associação empírica muito forte entre abertura econômica, grandes setores públicos e generosos sistemas de bem-estar (ver, p. ex., Cameron, 1978; Katzenstein, 1985).

Claro está que não deveríamos esperar, automaticamente, desenvolvimentos similares na América Latina, onde, tanto o fator das dotações como os históricos políticos são muito diferentes daqueles dos países desenvolvidos. Mesmo assim, estudos feitos, tanto por Garrett, como por Rodrik, revelam, empiricamente, que a abertura do comércio leva a economias públicas maiores nos países menos desenvolvidos, tanto quanto nos desenvolvidos (Garrett, 1999; Rodrik, 1997). 
Robert R. Kaufman e Alex Segura-Ubiergo

Várias são as razões pelas quais os efeitos perturbadores do aumento da concorrência internacional podem levar os governos dos países menos desenvolvidos a ampliar seus compromissos com gasto social. Independentemente de seu papel específico na economia internacional ou dos ganhos líquidos trazidos pela liberalização do comércio, os países que aumentam sua exposição aos mercados internacionais tendem a experimentar deslocamentos sociais, incertezas e efeitos distributivos desiguais. Isto, por sua vez, gera um potencial de instabilidade política e/ou reação contra as políticas econômicas orientadas para o mercado. Assim, há incentivo para que governos e empresas evitem tais ameaças, fazendo transferências de bem-estar para setores sociais ou regiões geográficas que tenham ficado para trás no processo de mudança.

Mais ainda, assim como nos países desenvolvidos, a maior exposição ao comércio pode também fortalecer os incentivos à utilização do gasto social para elevar o nível de qualificação e produtividade da força de trabalho. Na medida em que o investimento público em "capital humano" fornece um bem coletivo ao setor privado, os grupos empresariais podem acolher com simpatia tais gastos, ou até fazer pressão por eles. Observamos, nesse ponto, que o termo "hipótese da compensação" é um tanto enganoso se presumirmos que a expansão do gasto social é necessariamente menos "eficiente" que sua redução. Pelo contrário, elevando a qualificação da força de trabalho e assegurando estabilidade política, os grandes Estados de Bem-Estar podem fornecer bens coletivos que aumentem a competitividade da economia nos mercados internacionais.

\section{Políticas Internas}

A adoção de estratégias de "eficiência" ou de "compensação" pelos governos pode, também, depender dos meios de que dispõem os cidadãos para se mobilizar em torno dos interesses econômicos e para cobrar a responsabilidade dos governos. Duas outras etapas de fatores políticos e institucionais podem, portanto, influenciar, também, o gasto social à medida que as economias ficam mais abertas. Uma delas é o equilíbrio de forças entre os grupos de interesse e as organizações partidárias. Nos países da OCDE, sindicatos fortes e governos social-democratas têm, geralmente, constituído as forças preponderantes por trás da expansão dos sistemas de bem-estar. É lícito supor que também sejam forças importantes de resistência aos cortes, em- 
Globalização, Política Interna e Gasto Social na América Latina...

bora isso seja objeto de algum debate nos casos da OCDE (Pierson, 1996; Hicks, 1999).

Na América Latina, como em outros países menos desenvolvidos, os sindicatos são notoriamente fracos, pelo menos em comparação com seus correspondentes da Europa Ocidental. Mais ainda, as diferenças entre os países da região são extremamente difíceis de serem aferidas sistematicamente. Um recente estudo de Nita Rudra tenta contornar esse problema da aferição, destacando as variações nas condições do mercado de trabalho e tomando-as como representação do poder de barganha das organizações trabalhistas. Em uma amostra global dos países menos desenvolvidos, Rudra verifica que o gasto social com seguridade varia na razão direta da proporção de mão-de-obra não qualificada, e inversa da reserva de mão-de-obra "excedente". Por outro lado, ainda nos faltam os indicadores mais diretos e confiáveis da força organizacional (número de membros, coesão etc.) que caracterizam os estudos da OCDE.

Neste trabalho, adotamos uma abordagem mais direta desse problema, enfocando a orientação política e as bases constituintes dos partidos que apóiam os presidentes em exercício. Como discutiremos abaixo, as transferências de seguridade social defendidas pelos partidos de "orientação popular" na América Latina podem, às vezes, beneficiar suas bases operárias, mas apresentam um impacto negativo nas rendas dos trabalhadores rurais e do setor informal. Mesmo quando as transferências buscadas por tais partidos não chegam aos muito pobres, podemos levantar a hipótese de que o gasto social terá maior probabilidade de se manter em governos eleitos com o apoio destes.

Finalmente, no âmbito da América Latina e no contexto dos países menos desenvolvidos, precisamos indagar, mais explicitamente, se a democracia em si "faz alguma diferença". Este ponto tem sido objeto de discussão na literatura sobre reforma econômica e social. Um dos argumentos é que a distinção geral não tem muita relevância explicativa e que é mais importante enfocar características mais específicas como o modelo constitucional, os sistemas de partidos e as políticas partidárias (Haggard e Kaufman, 1995). Uma perspectiva alternativa consiste em um ponto teórico relativamente direto: os governos democráticos enfrentam pressões de uma massa de eleitores para forne- 
Robert R. Kaufman e Alex Segura-Ubiergo

cer serviços sociais. Assim sendo, é mais provável que atendam às demandas por "compensação" que os governos autoritários.

A solução desse problema é complicada pelo fato de, como observamos acima, muitos serviços sociais serem distribuídos desigualmente na América Latina ${ }^{2}$. Ainda assim, eles chegam a parcelas significativas das classes média e operária da população — os setores sociais que, mais provavelmente, comparecerão às urnas. Por essa razão, a distinção entre democracias eleitorais e autocracias pode ser considerada um fator causal potencialmente importante nas decisões de gasto. Recente estudo feito por Brown e Hunter (1999) revela que as democracias latino-americanas, de fato, têm maior probabilidade de manter a seguridade social e os gastos com saúde e educação em períodos de arrefecimento da economia (ver, também, Avelino, 2000). Neste artigo, elaboramos sobre seu trabalho, indagando se o impacto dos regimes políticos é afetado pela integração aos mercados internacionais.

\section{A Amostra Latino-Americana}

Estas e outras questões a elas relacionadas receberam considerável atenção em estudos quantitativos dos países da OCDE e, mais recentemente, foram exploradas em amostras globais (ver os estudos feitos por Garrett, 1999; Rodrik, 1997; Rudra, no prelo). Nossa amostra da América Latina não tem o benefício dos refinados dados disponíveis na OCDE, e falta-lhe o amplo alcance empírico das amostras mais abrangentes. Por outro lado, o fato de nos concentrarmos nos países dessa região apresenta algumas vantagens.

Primeiro, ao contrário de muitos outros países menos desenvolvidos e economias em transição, vários países latino-americanos têm, já há longo tempo, sistemas de bem-estar baseados em ocupação nos moldes dos sistemas europeus, com planos de pensão de benefícios definidos, serviços de saúde e salários-família. Por volta da década de 20, as bases desses sistemas já haviam sido estabelecidas na Argentina, no Uruguai e no Chile. Durante as décadas de 30 e 40, seguiu-se uma segunda leva de países, entre os quais Brasil, Costa Rica, México, Venezuela, Panamá e Colômbia (Mesa-Lago, 1978).

Apesar das ineficiências e das desigualdades distributivas, redes de segurança e serviços sociais cobriam parcelas significativas de suas 
Globalização, Política Interna e Gasto Social na América Latina...

respectivas sociedades. Pela década de 80 , as estimativas indicam que essa cobertura chegava a algo entre $62 \%$ e $96 \%$ da população economicamente ativa em, pelo menos, cinco países (Uruguai, Argentina, Chile, Brasil e Costa Rica), e entre 45\% e 53\% no Panamá, no México e na Venezuela (Mesa-Lago, 1989). Estes não são dados muito bons pelos padrões dos países desenvolvidos. No entanto, ao iniciar-se a "grande transformação" na América Latina, tais sistemas constituíam uma parte importante do "contrato social" que vinculava os cidadãos aos Estados.

A amostra da América Latina é interessante, também, pelas transformações políticas que varreram a região ao longo das duas últimas décadas. Os países latino-americanos estavam entre os primeiros Estados não europeus a juntar-se à "terceira onda" de democratização. $\mathrm{O}$ fato de essas transições políticas terem ocorrido mais ou menos ao mesmo tempo que a abertura econômica realça, de forma especial, se as democracias podem mitigar os potenciais efeitos negativos da globalização.

Finalmente, o âmbito limitado do cruzamento entre países de nossa amostra é parcialmente compensado pela qualidade e confiabilidade dos dados que puderam ser compilados, o que é particularmente importante em relação à medida da variável dependente. Nossa cobertura do gasto social contém alguns problemas que discutiremos abaixo, mas ela acrescenta algumas dimensões importantes a outros estudos de países menos desenvolvidos. Os dados agregados de gasto governamental utilizados nas amostras globais de Rodrik (1997) e Garrett (1999) são substitutos imperfeitos do gasto social, pelo menos na América Latina. A simples correlação entre gastos do governo central e gasto social como percentuais do PIB é alta $(0,81)$, mas as correlações com gastos de bem-estar per capita e como proporção do gasto governamental são apenas 0,51 e 0,31, respectivamente. Os dados de gastos, em vários outros estudos importantes, ou não incluem saúde e educação ou cobrem um período limitado de tempo.

Como essas outras medidas, a validade de nossos dados fica comprometida pelo fato de alguns dos problemas mais sérios dos sistemas de bem-estar dos países menos desenvolvidos envolverem falhas na organização e na distribuição de benefícios, não no financiamento por si só (Huber, 1996; Nelson, 2000). Por esse motivo, como sugerimos acima, todos os tipos de mensurações de gastos substituem de forma 
demasiadamente imperfeita os benefícios que os cidadãos de fato recebem. É plausível presumir, contudo, que mesmo sistemas relativamente eficientes e eqüitativos exigirão compromissos financeiros significativos do setor público. Os tipos de mensuração de gastos usados neste e em outros estudos dão, pelo menos, uma indicação grosseira dos recursos que os governos estão prontos a dedicar às necessidades sociais.

\section{AS VARIÁVEIS E O MODELO}

\section{As Variáveis}

Gasto Social - Nossas variáveis de gastos sociais baseiam-se nos dados anuais do FMI (vários anos) sobre gastos públicos com seguridade, saúde e educação. Tais gastos, por sua vez, são medidos de três formas: em dólares per capita de 1995; como percentual do PIB; como parcela dos gastos do governo central, excluídos os pagamentos dos juros da dívida pública. Estes são excluídos dos gastos totais dos governos porque, em parte, são produto da dívida acumulada de longo prazo, que não pode ser reduzida rapidamente pelo governo em exercício, enquanto o que nos interessa é analisar como tais governos estabelecem as prioridades orçamentárias. Apresentamos os resultados de todas as variáveis dependentes, pois cada uma delas captura tipos relativamente distintos de esforços pelo bem-estar. Como acabamos de observar, a parcela fiscal dos gastos sociais reflete as prioridades estabelecidas no interior do setor público. Os gastos como percentuais do PIB indicam as prioridades na distribuição dos recursos na economia nacional como um todo. Os gastos em bem-estar per capita medem o valor dos recursos potencialmente à disposição dos beneficiários.

Infelizmente, como em outros estudos de gastos públicos com grande número de casos de países em desenvolvimento, há dados disponíveis apenas para os gastos do governo central ${ }^{3}$. Isso representa um problema sério para nossa análise, porque, no final da década de 80 , diversos sistemas federais começaram a transferir parte da responsabilidade pelos programas sociais para os governos estaduais. Procuramos resolver este problema de várias maneiras, nenhuma delas totalmente satisfatória, no entanto. Em primeiro lugar, é preciso observar que nosso conjunto de dados se estende até a década de 70, enquanto os principais impulsos de descentralização fiscal não ocorre- 
Globalização, Política Interna e Gasto Social na América Latina...

ram, na maioria dos países, antes da de 90 . Mesmo aí, os governos federais retiveram a responsabilidade pelo pagamento de pensões e vários serviços sociais. Finalmente, não verificamos diferenças importantes nos resultados de nosso modelo quando excluímos Brasil e Argentina, os dois países mais descentralizados durante a maior parte do período coberto pelo modelo.

Após declínio durante a crise fiscal da década de 80, o gasto social na América Latina como um todo cresceu substancialmente durante os anos 90 , período em que a região se integrou cada vez mais à economia mundial. Superficialmente, pode parecer que a conjugação dos aumentos nos gastos com a abertura econômica vem comprovar a hipótese da compensação. No entanto, é impossível avaliar a conexão causal entre as duas tendências sem levar em conta o efeito de outros fatores que também podem influenciar o gasto social, como fazemos neste estudo.

É importante enfatizar, ainda, que a velocidade da mudança variou consideravelmente de país para país. Ao longo dos 25 anos cobertos por nosso modelo, a mudança média anual do gasto per capita foi de US\$ 7,30, enquanto o desvio-padrão foi de US\$ 52,39. Em termos de percentuais do orçamento e do PIB, as mudanças foram, em média, de $0,16 \%$ e $0,08 \%$, respectivamente, enquanto os desvios-padrão correspondentes foram de 4,82 e 1,31. Durante a tendência ascendente da década de 90, as taxas anuais de mudança variaram, de um mínimo de $-1,7 \%$ em Honduras a $22 \%$ no Peru, e mesmo no final da década, os gastos em El Salvador, na Guatemala e na Venezuela continuavam abaixo dos máximos verificados antes da década de 80 (ECLAC, 1999). Há, portanto, enormes variações na variável dependente.

Globalização - A exposição aos mercados internacionais é medida de duas formas. Seguindo as práticas convencionalmente adotadas na maior parte da literatura sobre globalização (ver, p. ex., Hicks e Swank, 1992; Huber e Stephens, 2001; Iverssen e Cusack, 2000; Rodrik, 1997; Garrett, 1999), a integração comercial foi calculada como importações+exportações/PIB. Essa medida é afetada pelo tamanho da economia e pelas variações na taxa de câmbio, mas a inclusão de países simulados e taxas de câmbio como variáveis explicativas em nosso modelo corrige tais efeitos. 
Robert R. Kaufman e Alex Segura-Ubiergo

Para a abertura aos mercados internacionais de capitais, usamos um índice de liberalização da conta de capitais desenvolvido por Morley et alii (1999) que reflete a extensão do controle setorial sobre os investimentos estrangeiros, os limites à repatriação de lucros e juros, os controles dos créditos externos a tomadores nacionais de empréstimo e os fluxos de saída de capital. Utilizamos esse índice de políticas em lugar de uma medida mais direta dos fluxos de capitais, porque estes, geralmente, indicam volatilidade macroeconômica, em vez de abertura, especialmente em uma região extraordinariamente instável como a América Latina. Da mesma forma que o uso de índices de comércio, essa escolha segue uma prática comum na literatura sobre globalização (ver, Garrett, 1999; Quinn, 1997).

Presidentes com Base Popular - Para aferir o equilíbrio relativo de poder partidário, codificamos todos os chefes de Estado em termos da orientação política de sua base partidária. Os presidentes são codificados como de base popular se vierem de partidos com vínculos historicamente estreitos com os sindicatos trabalhistas (por exemplo, os peronistas na Argentina, ou a Ação Democrática na Venezuela), e/ ou se seus partidos tiverem orientação programática de longa data voltada para "o setor popular" (por exemplo, o MNR na Bolívia, ou o PLN na Costa Rica). É importante enfatizar que nossa codificação não leva em conta se os indivíduos na Presidência são, eles próprios, conservadores ou de tendência esquerdista em suas preferências políticosociais. Na verdade, alguns líderes "de base popular", como Carlos Menem, pendem decisivamente para a direita. A questão é, no entanto, se seus comportamentos políticos são restringidos por suas bases constituintes ou pelos partidos que os apóiam, questão que deve ser resolvida empiricamente, antes que por definição. Aqui, de novo, essa abordagem acompanha um problema tipicamente colocado sobre os países da OCDE, qual seja, se os partidos de "esquerda" se comportam de forma diferente dos partidos de direita quando chegam ao poder.

Codificamos, também, alguns regimes autocráticos como "de base popular", segundo a forma como os especialistas caracterizaram suas principais coalizões de apoio, ou suas estratégias para construção de apoio político. Um exemplo disso é o regime militar que assumiu o poder no Peru em 1968, e outro é o regime de partido dominante do México. Conquanto tenhamos mais confiança na validade dessa codificação para os regimes democráticos, é interessante verificar se, in- 
dependente do tipo de regime, as "bases populares" determinam o comportamento.

Democracia - Seguindo Álvarez et alii (1996), utilizamos uma medida dicotômica de democracia baseada no conjunto de dados Polity III de Jaggers e Gurr (1996). Os países foram classificados subtraindo-se a escala de 10 pontos para "autocracia" da escala de 10 pontos para "democracia". Qualquer país que obtenha pelo menos 6 pontos é codificado como democrático, e os demais como autoritários ${ }^{4}$. Conforme observamos na seção anterior, esperávamos que, à medida que seus países se integrassem mais na economia internacional, os governos democraticamente eleitos tivessem um efeito positivo nas alterações dos gastos sociais.

Variáveis de Controle - No decorrer de nossa pesquisa, examinamos o impacto de um grande número de variáveis de controle, entre as quais população, urbanização, dívida pública, receitas governamentais, simulações de inflação, taxas de câmbio e choques de PIB, PIB registrado e crescimento do PIB. A maioria delas foi excluída do modelo final para evitar problemas de múltiplas colinearidades e tornar nossa apresentação mais clara. Eventuais escolhas, de quais controles incluir no modelo final, basearam-se na força de nossas expectativas teóricas iniciais, na existência de cobertura completa de dados e nos testes de informações de Chow e Aiken na determinação da contribuição dos controles para a variação total explicada no modelo. Deve-se enfatizar, contudo, que nenhum dos controles excluídos desse modelo alterava nossas descobertas básicas relevantes.

A especificação final do modelo incorpora os efeitos da composição demográfica, incluindo controles de idade da população — ou, onde isso é relevante, os percentuais de crianças e de dependentes idosos - e controles de PIB per capita para a "lei de Wagner", que postula que o tamanho do governo aumenta com a riqueza da economia. Incluímos, também, variável "quebra de resultados" utilizada pelos economistas da OCDE e que deriva da comparação do valor real do PIB, em um dado ano, com o valor que seria de se esperar em função da tendência de crescimento subjacente. Essa variável pode ser utilizada para avaliar os efeitos dos ciclos de negócios nos gastos sociais. Um sinal positivo indicaria que tais efeitos seguem um padrão pró-ciclo, enquanto uma relação negativa indicaria um padrão contracíclico. A utilização da medida da quebra de resultados como controle elimina 
a possibilidade de equívoco, imaginando que outras variáveis verificadas sejam causadas por essas relações cíclicas.

Como as mudanças no gasto social podem ser, na verdade, efeitos de alterações mais gerais nos gastos governamentais, incluímos estes últimos como outro controle, assim como as flutuações de taxas de câmbio também foram incluídas para levar em conta seus possíveis efeitos no comércio e na abertura da conta de capitais. Seguindo Krugman (1999), estimamos a taxa real de câmbio multiplicando a taxa nominal de cada país pela razão do índice local de inflação dos preços ao consumidor em relação ao índice de inflação dos preços ao consumidor nos Estados Unidos. Uma descrição mais completa de todas essas variáveis pode ser encontrada no Apêndice Técnico.

Finalmente, o modelo também leva em conta os efeitos do tempo e de efeitos fixos. Décadas simuladas são usadas para contemplar as importantes diferenças nas condições regionais e internacionais ao longo do período considerado. A primeira delas abrange os anos que antecederam a crise da dívida - de 1973 a 1981 —, e a segunda vai de 1982 a 1990, anos geralmente marcados por recessão econômica e dolorosos ajustes estruturais. Finalmente, a última cobre o período de recuperação econômica que se verificou durante a primeira metade da década de $90^{5}$. Em todas as especificações do modelo foram incluídas simulações de países. Elas corrigem fatores que podem afetar a abertura econômica e/ou o gasto com bem-estar de um país a longo prazo, como o tamanho da população e do território, a riqueza e o histórico político a longo prazo etc.

\section{O Modelo}

O modelo de série temporal que construímos leva em conta a importante distinção entre análises de diferenças entre países e a análise das mudanças ocorridas dentro de um mesmo país ao longo do tempo (ver Garrett, 1999; Huber e Stephens, 2001). As diferenças do Estado de Bem-Estar entre países, argumenta Garrett (1999), provavelmente não variarão durante longos períodos porque são influenciadas ou por fatores históricos que operam a longo prazo, ou por condições estruturais que só se alteram lentamente. As causas de tais diferenças são melhor avaliadas estatisticamente através de análises em que as variáveis-chave de explicação (abertura, força da esquerda etc.) sejam expressas como propriedades de longo prazo do sistema. Em relação a 
Globalização, Política Interna e Gasto Social na América Latina...

isso, comentamos, de passagem, que, em contraste com os casos da OCDE, as regressões de MQOs dos cortes transversais não mostram relação significativa entre abertura e tamanho do governo na América Latina. Alguns países com economias abertas, como o Panamá, de fato têm governos grandes, mas muitas outras sociedades centro-americanas pequenas não. Esses resultados, mais ainda, não são afetados pelos controles de PIB e democracia.

No presente trabalho, contudo, estamos interessados nas mudanças nos gastos sociais que, presumivelmente, são influenciadas mais diretamente por processos dinâmicos de globalização e por pressões políticas contemporâneas. Usamos um modelo para correção de erro adequado, precisamente, esse propósito.

Como discutimos na Introdução, tivemos particular cuidado ao tratar os problemas que mais comumente afetam os modelos de corte transversal com séries temporais. Seguimos a metodologia sugerida por Beck e Katz $(1995 ; 1996)$, pela qual o uso de MQOs com errospadrão corrigidos em painéis trata dos problemas da heteroscedasticidade corrigida por painel e da correlação espacial, com uma variável dependente defasada corrigindo a correlação serial.

Utilizamos variáveis simuladas de países e simulações de tempo para controlar os efeitos fixos específicos de países e tempos. O uso de efeitos fixos vem se tornando a norma em estudos do Estado de BemEstar com painéis e é particularmente importante em nosso modelo, porque a maioria das variáveis muda mais entre as unidades que ao longo do tempo. O uso de erros-padrão corrigidos por painéis geralmente produz resultados bastante conservadores, já que tende a aumentar os erros-padrão das estimativas. Mais ainda, a inclusão de variáveis simuladas tende a deflacionar a relevância estatística das outras variáveis explicativas (Sayrs, 1989). Esse método traz em si algum risco de as hipóteses causais serem rejeitadas prematuramente. Por outro lado, também aumenta nossa confiança de que os resultados que surgem como relevantes não são conseqüência de premissas estatísticas pouco confiáveis ou de métodos econométricos inadequados $^{6}$.

A versão genérica do modelo pode ser definida como ${ }^{7}$ :

$$
\Delta \mathrm{Y}_{\mathrm{i}, \mathrm{t}}=\mathrm{D} \alpha+\mathrm{Y}_{\mathrm{i}, \mathrm{t}-1} \cdot \beta_{\phi}+\Delta \mathrm{X}_{\mathrm{i}, \mathrm{t}-1} \cdot \beta_{\mathrm{k}}+\mathrm{X}_{\mathrm{i}, \mathrm{t}-1} \cdot \beta_{\mathrm{j}}+\mathrm{T} \lambda+\epsilon_{\mathrm{i}, \mathrm{t}}(1),
$$


onde $Y_{i, t}$ representa os gastos com bem-estar de um país $i$ durante o ano $t$; X é um vetor de variáveis independentes, D de variáveis simuladas de países ou efeitos fixos e T é um vetor de efeitos temporais. As especificações da variável dependente são medidas como primeiras diferenças, e as variáveis independentes incluíram os níveis defasados de gastos de bem-estar em cada variável independente e as alterações anuais $(\Delta)$ nas variáveis independentes.

Esse tipo de modelo se baseia na idéia de que as variáveis dependentes e independentes estão em uma relação de equilíbrio a longo prazo, mas que há importantes efeitos, ou temporários ou a curto prazo (Greene, 2000; Banerjee et alii, 1993). Como já foi observado acima, as "variáveis $\Delta$ " à direita da equação medem as mudanças em primeiras diferenças usadas para estimar as alterações anuais nas variáveis dependentes. Seu impacto geral nos gastos depende da magnitude do coeficiente de regressão $\left(\beta_{\mathrm{k}}\right)$ associado à variável da primeira diferença e à persistência da alteração ao longo do tempo, o que, por sua vez, depende do coeficiente da variável dependente defasada $(\phi)$. Em outras palavras, se uma alteração de $10 \%$ no comércio $\Delta$ se sustentar nos anos seguintes, isso terá um efeito maior do que teria se a mudança fosse subseqüentemente invertida.

Os coeficientes $\left(\beta_{\mathrm{j}}\right)$ das variáveis dos níveis $\left(\mathrm{X}_{\mathrm{i}, \mathrm{t}-1}\right)$ medem os efeitos a longo prazo da variável dependente. Eles permitem avaliar se as tendências na variável independente têm relação causal com as tendências no longo prazo da variável dependente. Quando o coeficiente de regressão $\left(\beta_{\mathrm{j}}\right)$ for estatisticamente significativo, isto indicará que há uma relação causal a longo prazo entre essas tendências. Estima-se a força dessa relação dividindo-se o coeficiente de regressão $\left(\beta_{\mathrm{j}}\right)$ por $(-\phi)$, a taxa anual à qual as alterações não previstas da variável Y retornam à linha da tendência (ver Apêndice Técnico).

A inclusão de variáveis, tanto de primeira diferença quanto de níveis, é uma exigência estatística do modelo de correção de erro. Já a interpretação de seu papel causal exige decisões teóricas e conceituais. As medidas demográficas usadas como variáveis de controle, por exemplo, alteram-se lentamente ano a ano, e seus efeitos atuarão, mais provavelmente, através de variáveis de níveis. Em outros casos, tanto as modificações de primeiras diferenças como as tendências a longo prazo podem ter significados relevantes. Pode-se, por exemplo, presumir que as variáveis de primeira diferença para democracia ou go- 
Globalização, Política Interna e Gasto Social na América Latina...

vernos de base popular medem os efeitos de uma transição de regime ou de uma mudança de governo em determinado ano, enquanto as variáveis de níveis medem o efeito de prazo mais longo de tais mudanças, dentro de um determinado país. Na medida em que os efeitos do comércio sobre o gasto atuam por intermédio dos esforços de lobby dos grupos empresariais expostos à concorrência internacional, é maior a probabilidade de que venham a ser sentidos a longo prazo. Por outro lado, como sugerimos abaixo, os governos, que vinculam reformas estruturais a reduções no gasto, podem também produzir efeitos importantes a curto prazo, que seriam capturados pelas variáveis de primeiras diferenças.

\section{RESULTADOS DO GASTO SOCIAL AGREGADO}

As estimativas de alterações nos níveis agregados de gasto estão indicadas no Quadro 1. Para maior clareza na apresentação, não incluímos no quadro nem os países simulados nem os efeitos das primeiras diferenças de diversas variáveis de controle que parecem funcionar, primordialmente, como tendências de prazo mais longo. De modo geral, os modelos explicam entre $35 \%$ e $46 \%$ da variação no gasto social, o que é um ajuste razoavelmente bom. Um modelo que usasse apenas variáveis de níveis levaria, tipicamente, a um $R^{2}$ muito mais alto, mas isso apenas porque a variável dependente defasada inflacionaria artificialmente a variação total explicada.

Na maior parte do tempo, os coeficientes das variáveis de controle seguem na direção esperada, e são uniformemente consistentes com as expectativas quando chegam aos patamares-padrão de relevância estatística. De forma nada surpreendente, as tendências do gasto do governo central têm importante impacto. À medida que cresce o governo central, cresce também o gasto com bem-estar, tanto per capita como em percentual do PIB. O impacto da quebra de resultados é significativo para o gasto/PIB e positivo para as outras especificações, o que indica que o gasto social na América Latina tende a ser pró-cíclico. Os coeficientes das décadas simuladas medem os efeitos nos gastos durante as décadas de 70 e 80 em comparação com aqueles da de 90, a categoria omitida. Como se esperava, o fato de tais coeficientes serem negativos e relevantes indica que, tudo o mais se mantendo constante, nas décadas de 70 e 80 o gasto foi menor que na de 90 . Mais ainda, como já se observou, mesmo quando as variáveis individuais de controle não atingem os níveis-padrão de relevância, os tes- 
Robert R. Kaufman e Alex Segura-Ubiergo

Quadro 1

Determinantes do Gasto Social em Países Latino-Americanos, 1973-1997

\begin{tabular}{|c|c|c|c|}
\hline & D.B.ESTARCAP & D.B.ESTARPUB & D.B.ESTARPIB \\
\hline L. PIBCAP & $\begin{array}{c}0,04578^{* * *} \\
(2,95)\end{array}$ & $\begin{array}{c}0,00084 \\
(0,77)\end{array}$ & $\begin{array}{c}-0,00015 \\
(0,65)\end{array}$ \\
\hline L. Quebra de Resultados & $\begin{array}{c}1,16775 \\
(0,86)\end{array}$ & $\begin{array}{c}0,18411 \\
(1,02)\end{array}$ & $\begin{array}{c}0,08660^{* * *} \\
(2,64)\end{array}$ \\
\hline L. Idade65 & $\begin{array}{c}26,62502^{* *} \\
(2,56)\end{array}$ & $\begin{array}{c}-0,72316 \\
(0,66)\end{array}$ & $\begin{array}{c}0,16036 \\
(0,82)\end{array}$ \\
\hline L. Governo & $\begin{array}{c}2,91540^{* * *} \\
(3,22)\end{array}$ & $\begin{array}{c}0,24923 \\
(1,38)\end{array}$ & $\begin{array}{c}0,08819^{* * *} \\
(3,72)\end{array}$ \\
\hline D. Governo & $\begin{array}{c}10,19899^{* * *} \\
(8,92)\end{array}$ & $\begin{array}{c}-0,20322 \\
(0,69)\end{array}$ & $\begin{array}{c}0,26326^{* * *} \\
(10,68)\end{array}$ \\
\hline L. Taxa de Câmbio & $\begin{array}{c}0,00665 \\
(0,92)\end{array}$ & $\begin{array}{c}-0,00168 \\
(1,08)\end{array}$ & $\begin{array}{c}-0,00022 \\
(1,13)\end{array}$ \\
\hline D. Taxa de Câmbio & $\begin{array}{c}0,02540 \\
(1,56)\end{array}$ & $\begin{array}{c}0,00278 \\
(0,75)\end{array}$ & $\begin{array}{c}0,00070^{*} \\
(1,66)\end{array}$ \\
\hline L. Comércio & $\begin{array}{c}-0,89904^{* * *} \\
(3,04)\end{array}$ & $\begin{array}{c}-0,07027^{* *} \\
(1,99)\end{array}$ & $\begin{array}{c}-0,01662^{* *} \\
(2,48)\end{array}$ \\
\hline D. Comércio & $\begin{array}{c}-1,47504^{* * *} \\
(4,61)\end{array}$ & $\begin{array}{c}-0,10286^{* *} \\
(2,30)\end{array}$ & $\begin{array}{c}-0,03935^{* * *} \\
(5,05)\end{array}$ \\
\hline L. Capital & $\begin{array}{c}-0,44671^{*} \\
(1,89)\end{array}$ & $\begin{array}{c}0,06978^{* *} \\
(2,21)\end{array}$ & $\begin{array}{c}-0,00007 \\
(0,01)\end{array}$ \\
\hline D. Capital & $\begin{array}{c}0,20770 \\
(0,51)\end{array}$ & $\begin{array}{c}0,09792^{*} \\
(1,78)\end{array}$ & $\begin{array}{c}0,00104 \\
(0,13)\end{array}$ \\
\hline L. Democracia & $\begin{array}{c}-12,32505 \\
(1,52)\end{array}$ & $\begin{array}{c}0,08369 \\
(0,06)\end{array}$ & $\begin{array}{c}-0,19032 \\
(1,04)\end{array}$ \\
\hline D. Democracia & $\begin{array}{c}-15,96276 \\
(1,05)\end{array}$ & $\begin{array}{c}1,05218 \\
(0,40)\end{array}$ & $\begin{array}{c}-0,52492 \\
(1,59)\end{array}$ \\
\hline L. Popular & $\begin{array}{c}-11,20824^{*} \\
(1,73)\end{array}$ & $\begin{array}{c}1,17233 \\
(1,18)\end{array}$ & $\begin{array}{c}-0,04741 \\
(0,32)\end{array}$ \\
\hline D. Popular & $\begin{array}{c}2,07271 \\
(0,29)\end{array}$ & $\begin{array}{c}2,41128^{* *} \\
(2,11)\end{array}$ & $\begin{array}{c}0,04107 \\
(0,25)\end{array}$ \\
\hline Dec-70 & $\begin{array}{c}-38,24258^{* * *} \\
(3,41)\end{array}$ & $\begin{array}{c}-6,36836^{* * *} \\
(3,46)\end{array}$ & $\begin{array}{c}-0,92348^{* * *} \\
(3,40)\end{array}$ \\
\hline Dec- 80 & $\begin{array}{c}-36,30183^{* * *} \\
(4,61)\end{array}$ & $\begin{array}{c}-4,56418^{* * *} \\
(3,14)\end{array}$ & $\begin{array}{c}-0,93233^{* * *} \\
(4,85)\end{array}$ \\
\hline Var. Dep. Defasada & $\begin{array}{c}-0,28097^{* * *} \\
(3,14)\end{array}$ & $\begin{array}{c}-0,61602^{* * *} \\
(4,78)\end{array}$ & $\begin{array}{c}-0,27955^{* * *} \\
(4,28)\end{array}$ \\
\hline Constante & $\begin{array}{c}-378,22368^{* * *} \\
(2,63)\end{array}$ & $\begin{array}{c}32,19257^{* *} \\
(2,42)\end{array}$ & $\begin{array}{c}1,81409 \\
(0,66)\end{array}$ \\
\hline R-quadrado & 0,4600 & 0,3589 & 0,4567 \\
\hline Prob $>$ Wald Chi2 & 0,0000 & 0,0001 & 0,0000 \\
\hline Observações & 284 & 284 & 284 \\
\hline
\end{tabular}

Estatísticas z corrigidas por painel entre parênteses.

* significativo a $10 \% ;{ }^{* *}$ significativo a $5 \% ;{ }^{* *}$ significativo a $1 \%$. 
Globalização, Política Interna e Gasto Social na América Latina...

tes de Chow e os critérios de informação de Aiken mostram que, em geral, elas contribuem, significativamente, para a variação global no modelo.

Quando nos voltamos para as variáveis materiais enfatizadas na discussão geral sobre globalização, a descoberta mais surpreendente consiste nos fortes efeitos negativos das aberturas comerciais. Em todas as especificações da variável dependente, tanto os efeitos a curto como os a longo prazo atravessam os patamares superiores de relevância do modelo de correção de erro. O modelo revela que os efeitos da integração comercial são independentes das circunstâncias "conjunturais" das décadas de 80 e 90, do ciclo de negócios, das alterações demográficas, das flutuações das taxas de câmbio e dos efeitos fixos por país. As variáveis comerciais também foram suficientemente robustas em relação a uma bateria de outros controles que, eventualmente, decidimos não incluir no modelo, entre os quais estão a inflação, as crises de inflação, os choques de taxas de câmbio e as quedas bruscas do PIB'.

Os coeficientes dos "níveis de comércio" podem ser interpretados como uma indicação de que deslocamentos seculares nas preferências e no poder relativo de setores empresariais, expostos à concorrência internacional, reduzem o aumento do gasto a longo prazo. A esse respeito, tais setores são bastante coerentes com as "hipóteses da eficiência". Conforme discutimos no Apêndice Técnico, estima-se o impacto material dessa variável dividindo o coeficiente de regressão $\left(\beta_{\mathrm{j}}\right)$ pelo valor negativo da variável dependente defasada $(\phi)$. Mantendo-se o resto constante, um aumento de 10\% no comércio entre 1973 e 1997 produz, a longo prazo, uma redução média de US $\$ 31$ no gasto social per capita, o que representa mais de $10 \%$ da média regional de US\$225. Pelo menos, cinco países (Chile, Costa Rica, República Dominicana, México e Uruguai) experimentaram aumentos muito maiores - de $25 \%$ a $50 \%$ na participação do comércio no PIB. Nestes casos, a redução prevista no gasto deveria variar entre US $\$ 78$ e US $\$ 156$. Nessas mesmas condições, o gasto como percentual do PIB cairia de $1,5 \%$ a 3,0\% e 2,9\% a 5,8\% como percentual dos gastos totais do governo, contra médias regionais de cerca de $7 \%$ e $46 \%$, respectivamente.

O efeito, a curto prazo, de um aumento no comércio também é importante, e o impacto cumulativo pode ser bem relevante se for sustentado ao longo do tempo. Por exemplo, houve 22 casos em que os países 
experimentaram um aumento de pelo menos 10 pontos na participação do comércio em seu PIB. Podemos simular os efeitos de tal aumento no México, que é mais ou menos a mediana da amostra em termos de gastos sociais e onde, na verdade, o comércio cresceu ainda mais em 1995. Considerando-se um aumento de 10 pontos no comércio em um ano, o gasto durante o primeiro ano cairia cerca de US $\$ 15$ per capita, 0,4\% do PIB e, mais modestamente, $1 \%$ do gasto governamental. Se este aumento for mantido (como foi no caso do México), o efeito cumulativo após cinco anos leva a declínio do gasto per capita de US\$200 para US\$155, e de 6,3\% para 5,1\% do PIB. A queda acumulada em sua participação no orçamento é consideravelmente menor, mas, ainda assim, cai de $46,6 \%$ para $45,0 \%^{10}$.

Apesar de serem geralmente fortes, esses efeitos de primeiras diferenças são difíceis de interpretar da mesma forma que os efeitos a longo prazo das variáveis de níveis. Conquanto estes últimos possam refletir pressões diretas ou esperadas de grupos empresariais, parece pouco provável que tais pressões sejam mobilizadas ou esperadas tão rapidamente em bases anuais. Uma explicação alternativa é que os efeitos a curto prazo refletem premissas feitas pelos próprios formuladores de política sobre a relação entre reforma estrutural e ajuste fiscal. Se os reformadores liberais virem tais ajustes como condição necessária para uma concorrência comercial "eficiente", por exemplo, podem iniciar cortes no gasto social independente de pressão dos interesses comerciais, provavelmente como componente de um "pacote" de reforma geral.

Para verificar essa possibilidade, reestimamos nosso modelo, substituindo nossa variável de razão de comércio por um índice de liberalização de política comercial desenvolvido por Morley et alii (1999). Os efeitos das mudanças de primeiras diferenças na política comercial foram expressivamente semelhantes aos do comércio $\Delta$, enquanto os coeficientes dos efeitos a longo prazo da política não foram significativos. O que está implícito é que diferentes mecanismos causais movem as reduções em gastos sociais a curto e a longo prazos. A curto prazo, essas reduções resultam de iniciativas das elites de políticas macroeconômicas. Se essas reformas forem sustentadas e o comércio se ampliar a longo prazo, as pressões para redução do gasto podem refletir alterações estruturais na economia e os interesses mais amplos dos próprios grupos produtores. 
Globalização, Política Interna e Gasto Social na América Latina...

Em contraste com o comércio, o Quadro 1 mostra que a liberalização da conta de capitais não tem impacto consistente sobre o gasto social. A significância dos efeitos é sensível às outras variáveis incluídas no modelo e os sinais não são robustos em todas as especificações alternativas de gasto social ${ }^{11}$. Uma implicação é que a principal pressão pela redução de gastos vem de interesses de produtores expostos à concorrência, e não de uma preocupação mais geral com o estabelecimento de "credibilidade" nos mercados financeiros internacionais. Para os produtores, aumentos em gastos com bem-estar representam folhas de pagamento mais altas, o que se reflete diretamente em seus lucros. Assim, eles têm incentivo para fazer lobby contra a ampliação dos comprometimentos com o bem-estar (Frieden, 1991; Rodrik, 1997). Os detentores de ativos líquidos preocupam-se mais com os agregados macroeconômicos "fundamentais" que com os gastos com bem-estar, ou com os custos de mão-de-obra em si.

A redução dos controles sobre a movimentação de capitais, contudo, de fato amplia as opções de saída dos produtores e, quando a abertura de capital interage com aumentos de comércio (ver Quadro 2), os efeitos a longo prazo dessa interação são consistentemente negativos e atingem níveis-padrão de relevância, tanto para o gasto per capita como para a participação no orçamento ${ }^{12}$.

A Figura 1 fornece uma ilustração de como interpretar o impacto dos coeficientes de interação que serão mostrados no Quadro $4^{13}$. A figura abre esses coeficientes e nos permite acompanhar a forma como os aumentos do comércio afetam o gasto em diferentes níveis de abertura da conta de capital. No eixo " $X$ " plota-se o índice de abertura de capital entre zero e 100. A cada intervalo de 10 pontos nesta escala, estimamos o efeito que um aumento de $10 \%$ no comércio teria no gasto social per capita, sendo essas estimativas, então, plotadas no eixo " $Y$ ".

A figura mostra que se a conta de capital fosse totalmente fechada, uma expansão de $10 \%$ no comércio poderia ter um efeito positivo no gasto, mas, como fica evidenciado no coeficiente não interagido de níveis de comércio no Quadro 2, isto não é estatisticamente relevante. No "mundo real", os pontos no índice de capital variam de 20 a quase 90, e os efeitos no comércio tornam-se marcadamente negativos à medida que a conta de capital é aberta. Em um nível de 90 pontos, do qual a maioria dos países se aproximou pelo final da década de 90 , um aumento de $10 \%$ no comércio levaria a um decréscimo de US\$ 41 no 
Robert R. Kaufman e Alex Segura-Ubiergo

Quadro 2

Determinantes do Gasto Social em Quatorze

Países Latino-Americanos, 1973-1997

(Inclui um Coeficiente de Interação entre Comércio e Mobilidade de Capital)

\begin{tabular}{|l|c|c|c|}
\hline \multicolumn{1}{|c}{ (Inclui um Coeficiente de Interaçao entre Comercio e Mobilidade de Capital) } \\
\hline L. PIBCAP & D.ESTARCAP & D.B.ESTARPUB & D.B.ESTARPIB \\
\hline L. Quebra de Resultados & $0,05211^{* * *}$ & 0,00122 & $-0,00011$ \\
& $(3,27)$ & $(1,11)$ & $(0,48)$ \\
L. Idade65 & 0,77892 & 0,17950 & $0,08657^{* * *}$ \\
& $(0,57)$ & $(1,05)$ & $(2,62)$ \\
L. Governo & $34,91644^{* * *}$ & $-0,64500$ & 0,25328 \\
& $(2,93)$ & $(0,52)$ & $(1,15)$ \\
D. Governo & $3,30616^{* * *}$ & 0,29859 & $0,09605^{* * *}$ \\
L. Taxa de Câmbio & $(3,51)$ & $(1,58)$ & $(3,98)$ \\
& $10,25068^{* * *}$ & $-0,19431$ & $0,26407^{* * *}$ \\
D. Taxa de Câmbio & $(8,82)$ & $(0,65)$ & $(10,49)$ \\
& 0,00711 & $-0,00247$ & $-0,00025$ \\
L. Comércio & $(0,92)$ & $(1,51)$ & $(1,20)$ \\
D. Comércio & 0,02375 & 0,00195 & 0,00070 \\
& $(1,36)$ & $(0,50)$ & $(1,54)$ \\
L. Capital & 0,30471 & 0,08263 & $-0,00682$ \\
& $(0,46)$ & $(0,93)$ & $(0,53)$ \\
D. Capital & $-1,49695^{* * *}$ & $-0,07054$ & $-0,03724^{* * *}$ \\
L. Democracia & $(4,11)$ & $(1,46)$ & $(4,33)$ \\
& 0,26930 & $0,15297^{* *}$ & 0,00451 \\
D. Democracia & $(0,59)$ & $(2,42)$ & $(0,65)$ \\
L. Popular & 0,09342 & 0,08632 & $-0,00035$ \\
R-quadrado & $(0,22)$ & $(1,59)$ & $(0,04)$ \\
Prob>Wald Chi2 & $-9,04328$ & 0,84851 & $-0,13790$ \\
Observações & $(1,08)$ & $(0,56)$ & $(0,70)$ \\
Dopular & $-16,96761$ & 1,02375 & $-0,51814$ \\
Dec-70 & $(1,11)$ & $(0,39)$ & $(1,56)$ \\
Dec-80 & $-17,68635^{* *}$ & 0,66099 & $-0,09809$ \\
L. comércio*capital & $(2,38)$ & $(0,62)$ & $(0,57)$ \\
D. comércio*capital & 3,57339 & $3,59734^{* * *}$ & 0,11421 \\
& $(0,50)$ & $(3,05)$ & $(0,63)$ \\
& $-0,01802^{* *}$ & $-0,00223^{*}$ & $-0,00013$ \\
& $(2,22)$ & $(1,82)$ & $(0,89)$ \\
& $-0,01474$ & $-0,00193$ & $-0,00015$ \\
& $(1,54)$ & $(1,54)$ & $(0,82)$ \\
& $-34,78092^{* * *}$ & $-6,32199^{* * *}$ & $-0,86041^{* * *}$ \\
& $(2,86)$ & $(3,31)$ & $(2,95)$ \\
& $-34,16169^{* * *}$ & $-4,79902^{* * *}$ & $-0,90888^{* * *}$ \\
& $(4,02)$ & $(3,20)$ & $(4,40)$ \\
& $-0,30021^{* * *}$ & $-0,64301^{* * * *}$ & $-0,28627^{* * *}$ \\
& $(3,24)$ & $(4,89)$ & $(4,32)$ \\
& $-546,11518^{* * *}$ & 23,32253 & 0,32960 \\
& $(3,21)$ & $(1,62)$ & $(0,11)$ \\
& 0,4724 & 0,3757 & 0,4613 \\
& 0,0000 & 0,0013 & 0,0000 \\
& 273 & 273 & 273 \\
\hline & & &
\end{tabular}

Estatísticas z corrigidas por painel entre parênteses.

* significativo a $10 \%$; ${ }^{* *}$ significativo a $5 \%$; ${ }^{* *}$ significativo a $1 \%$. 
Globalização, Política Interna e Gasto Social na América Latina...

Figura 1

Efeito Condicional de um Aumento de $10 \%$ no Comércio sobre o Gasto per capita, em Função do Grau de Mobilidade de Capital

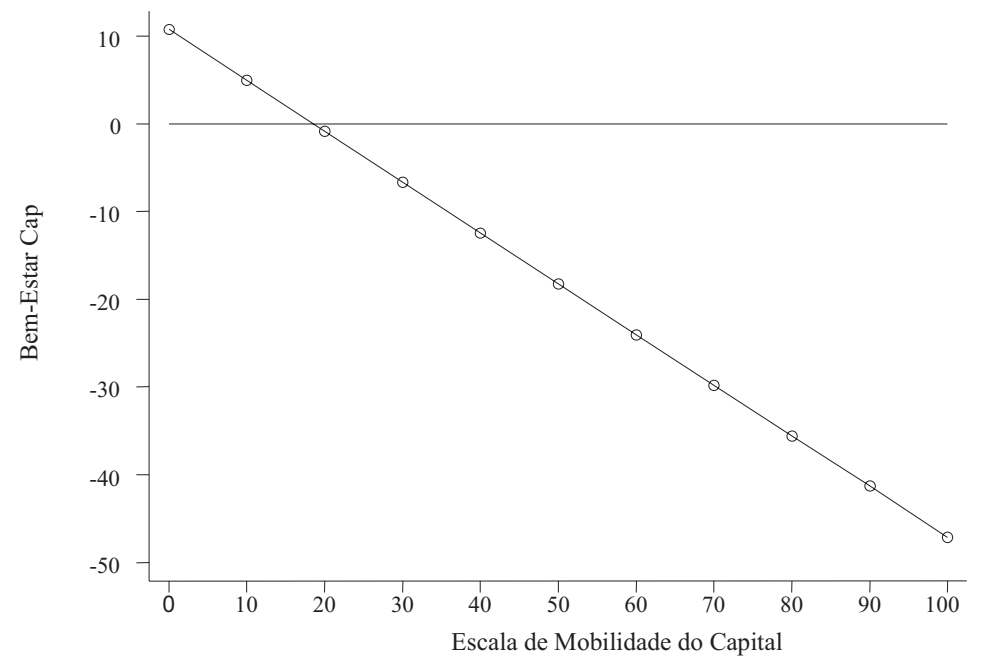

Nota: Esta figura foi criada usando o coeficiente de interação entre a variável de nível para comércio e a variável de nível para mobilidade de capital (ver Quadro 2). O coeficiente não interagido para comércio $(0,3124)$ mede o impacto do comércio nos gastos sociais quando a mobilidade de capital é zero. Para capturar os efeitos a longo prazo, o coeficiente condicional tem de ser dividido pela variável dependente defasada (em termos absolutos), e depois multiplicado pelo nível pertinente de mobilidade de capital.

gasto per capita. Obtivemos resultados comparáveis para cada uma das duas outras especificações de gasto: à medida que são removidos os controles sobre o capital, o comércio tem um efeito negativo e significativo no gasto.

Deixamos para a próxima seção uma discussão aprofundada das variáveis políticas. Notamos, aqui, apenas que em nossas especificações agregadas de gasto social os efeitos são geralmente fracos e contrariam as expectativas. Ao contrário de uma boa parte da literatura sobre os países da OCDE, os governos "de base popular" parecem, na verdade, gastar significativamente menos per capita que os governos alternativos, embora a curto prazo gastem uma parcela maior do orçamento.

Os regimes democráticos também não apresentam impactos previsíveis nos gastos sociais agregados, e não descobrimos nenhum efeito 
robusto de interação entre democracia e as outras variáveis independentes usadas no modelo. Ao contrário de Brown e Hunter (1999), por exemplo, uma vez que as variáveis de globalização são incorporadas no modelo, a democracia parece não reagir mais que as ditaduras às pressões demográficas e políticas, e não ser menos resistente a inflexões de baixa na economia. É bastante provável que esses resultados nulos e contra a intuição sejam produto de erro de mensuração. Discutiremos na seção seguinte que podemos obter um melhor entendimento dos efeitos das variáveis políticas se examinarmos a forma como elas afetam os diferentes tipos de gasto social.

\section{ABERTURA DO GASTO COM BEM-ESTAR: PENSÕES, SAÚDE E EDUCAÇÃO}

Tipicamente, os gastos com seguridade social, saúde e educação são combinados nas revisões analíticas do gasto social na América Latina (ECLAC, 1999; Brown e Hunter, 1999). Como já foi indicado, contudo, há motivos para crer que eles podem ser influenciados por lógicas políticas distintas. Assim, na presente seção, discriminamos o gasto social e reexaminamos os efeitos da globalização e das variáveis políticas sobre as transferências de seguridade social, de um lado, e os gastos em saúde e educação, para formação de "capital humano", de outro.

Há várias razões pelas quais os gastos com seguridade social poderiam ser mais suscetíveis às pressões pela "eficiência" da integração comercial e ter menos probabilidade de serem defendidos por regimes democráticos. Em primeiro lugar, a maior parte do gasto nessa categoria se destina ao pagamento de pensões que são financiadas, em parte, por impostos que incidem sobre as folhas de pagamento e têm impacto direto e transparente sobre o custo da mão-de-obra. Conseqüentemente, é de se esperar que os grupos empresariais façam pressões particularmente fortes para mantê-los baixos.

Mais importante ainda, os benefícios de pensão são, tipicamente, o componente mais regressivo do gasto social (ECLAC, 1999; Stallings e Peres, 2000). A categoria seguridade social compreende programas antipobreza e assistência dirigida aos pobres, mas os pagamentos de pensão em si fluem principalmente para a classe média e para os trabalhadores do setor formal, enquanto os custos do financiamento dos grandes déficits de fundos de pensão são socializados através de impostos genéricos ou de inflação (Mesa-Lago, 1989). Assim, com a possível exceção de alguns poucos sistemas de pensão altamente abrangentes, 
Globalização, Política Interna e Gasto Social na América Latina...

como os do Uruguai e da Costa Rica, os cortes no componente das pensões do gasto com seguridade social podem gerar menos protestos populares generalizados do que os que se têm verificado em muitos países europeus (ver, Esping-Andersen, 1990; 1999; Pierson, 1996).

É lícito imaginar que as restrições e oportunidades políticas sejam diferentes no caso dos gastos em educação e saúde, que contribuem para a formação de "capital humano". Embora o seguro saúde seja, às vezes, um componente das contas salários, tais gastos geralmente têm impacto direto menor nos custos de mão-de-obra e, do ponto de vista dos empregadores, podem apresentar resultados mais substanciais como investimentos em "capital humano".

Há, também, maior probabilidade de forte oposição política aos cortes nessas áreas. Apesar das desigualdades e da grave inadequação dos sistemas que prestam os serviços sociais, os gastos que contribuem para a formação de capital humano parecem, de fato, atingir uma parcela maior da população que os gastos com pensões (ECLAC, 1999). Estudos mais aprofundados sobre a Argentina, o Brasil, o Chile e a Colômbia, por exemplo, mostram que o gasto com saúde e educação constitui cerca de $75 \%$ do total de gastos sociais que é recebido pelas famílias do quintil mais baixo de renda e que, portanto, tem impacto positivo na distribuição geral de renda (Mostajo, 2000).

Em resumo, à medida que as economias latino-americanas ficam mais integradas nos mercados globais, os governos em exercício podem ter incentivos políticos mais fortes para proteger a saúde e a educação que a seguridade social. De fato, a simples correlação ( $r=-0,52$ de Pearson) entre essas medidas como percentual do orçamento implica um diferencial de custo bem marcante. Particularmente na era das "duras restrições orçamentárias", os governos parecem sofrer considerável pressão para definir prioridades.

Os Quadros 3 e 4 mostram como os gastos com seguridade social e saúde e educação são afetados pelas variáveis usadas no modelo geral. Em cada especificação de gasto, o impacto cumulativo dessas variáveis continua relativamente forte. $R^{2}$ varia de 0,30 a 0,45 , e as estimativas, tanto da globalização quanto das variáveis políticas, estão bastante alinhadas com nossas expectativas.

Tomemos, primeiro, as variáveis de globalização dos dois quadros. $\mathrm{O}$ Quadro 3 mostra que o impacto da variável de comércio, que vimos 
Robert R. Kaufman e Alex Segura-Ubiergo

\section{Quadro 3}

Determinantes do Gasto com Seguridade Social em Quatorze Países Latino-Americanos, 1973-1997

\begin{tabular}{|c|c|c|c|}
\hline & D.B.ESTARCAP & D.B.ESTARPUB & D.B.ESTARPIB \\
\hline L. PIBCAP & $\begin{array}{c}0,02908^{* * *} \\
(2,62)\end{array}$ & $\begin{array}{c}-0,00088 \\
(1,03)\end{array}$ & $\begin{array}{c}-0,00014 \\
(0,68)\end{array}$ \\
\hline L. Quebra de Produção & $\begin{array}{c}1,24428 \\
(0,98)\end{array}$ & $\begin{array}{c}0,37265^{* *} \\
(2,30)\end{array}$ & $\begin{array}{c}0,08093^{* *} \\
(2,48)\end{array}$ \\
\hline L. Idade65 & $\begin{array}{c}21,19791^{* *} \\
(2,06)\end{array}$ & $\begin{array}{c}0,17069 \\
(0,17)\end{array}$ & $\begin{array}{c}0,24539 \\
(1,24)\end{array}$ \\
\hline L. Governo & $\begin{array}{c}2,83378^{* * *} \\
(4,02)\end{array}$ & $\begin{array}{c}0,33744^{* *} \\
(2,52)\end{array}$ & $\begin{array}{c}0,08555^{* * *} \\
(4,82)\end{array}$ \\
\hline D. Governo & $\begin{array}{c}7,48964^{* * *} \\
(7,52)\end{array}$ & $\begin{array}{c}0,13620 \\
(0,61)\end{array}$ & $\begin{array}{c}0,17224^{* * *} \\
(7,65)\end{array}$ \\
\hline L. Taxa de Câmbio & $\begin{array}{c}0,00372 \\
(0,54)\end{array}$ & $\begin{array}{c}-0,00270^{* *} \\
(2,30)\end{array}$ & $\begin{array}{c}-0,00020 \\
(1,13)\end{array}$ \\
\hline D. Taxa de Câmbio & $\begin{array}{c}0,02053 \\
(1,34)\end{array}$ & $\begin{array}{c}0,00426 \\
(1,46)\end{array}$ & $\begin{array}{c}0,00061 \\
(1,59)\end{array}$ \\
\hline L. Comércio & $\begin{array}{c}-0,90592^{* * *} \\
(3,16)\end{array}$ & $\begin{array}{c}-0,06344^{* *} \\
(2,09)\end{array}$ & $\begin{array}{c}-0,01908^{* * *} \\
(3,05)\end{array}$ \\
\hline D. Comércio & $\begin{array}{c}-1,36058^{* * *} \\
(3,97)\end{array}$ & $\begin{array}{c}-0,12208^{* * *} \\
(3,11)\end{array}$ & $\begin{array}{c}-0,03658^{* * *} \\
(4,32)\end{array}$ \\
\hline L. Capital & $\begin{array}{c}-0,37124^{*} \\
(1,73)\end{array}$ & $\begin{array}{c}0,01552 \\
(0,63)\end{array}$ & $\begin{array}{c}-0,00295 \\
(0,66)\end{array}$ \\
\hline D. Capital & $\begin{array}{c}-0,02702 \\
(0,08)\end{array}$ & $\begin{array}{c}-0,00227 \\
(0,05)\end{array}$ & $\begin{array}{c}-0,00873 \\
(1,16)\end{array}$ \\
\hline L. Democracia & $\begin{array}{c}-17,09170^{* *} \\
(2,00)\end{array}$ & $\begin{array}{c}-1,44737 \\
(1,18)\end{array}$ & $\begin{array}{c}-0,37006^{*} \\
(1,82)\end{array}$ \\
\hline D. Democracia & $\begin{array}{c}-20,87167 \\
(1,42)\end{array}$ & $\begin{array}{c}-1,02922 \\
(0,52)\end{array}$ & $\begin{array}{c}-0,61415^{* *} \\
(2,05)\end{array}$ \\
\hline L. Popular & $\begin{array}{c}-9,62654 \\
(1,36)\end{array}$ & $\begin{array}{c}2,79490^{* * *} \\
(2,71)\end{array}$ & $\begin{array}{c}0,06050 \\
(0,35)\end{array}$ \\
\hline D. Popular & $\begin{array}{c}16,63647^{* *} \\
(1,99)\end{array}$ & $\begin{array}{c}3,96490^{* * *} \\
(3,46)\end{array}$ & $\begin{array}{c}0,55272^{* *} \\
(2,52)\end{array}$ \\
\hline Dec-70 & $\begin{array}{c}-42,70732^{* * *} \\
(3,85)\end{array}$ & $\begin{array}{c}-6,68163^{* * *} \\
(4,68)\end{array}$ & $\begin{array}{c}-1,04712^{* * *} \\
(4,03)\end{array}$ \\
\hline Dec-80 & $\begin{array}{c}-37,53505^{* * *} \\
(4,85)\end{array}$ & $\begin{array}{c}-4,80568^{* * *} \\
(4,16)\end{array}$ & $\begin{array}{c}-0,97314^{* * *} \\
(5,71)\end{array}$ \\
\hline Var. Dep. Defasada & $\begin{array}{c}-0,26595^{* * *} \\
(3,03)\end{array}$ & $\begin{array}{c}-0,56006^{* * *} \\
(5,42)\end{array}$ & $\begin{array}{c}-0,33047^{* * *} \\
(4,68)\end{array}$ \\
\hline Constante & $\begin{array}{c}-228,76248^{*} \\
(1,83)\end{array}$ & $\begin{array}{c}32,88103^{* * *} \\
(3,00)\end{array}$ & $\begin{array}{c}1,50973 \\
(0,59)\end{array}$ \\
\hline R-quadrado & 0,3754 & 0,3723 & 0,3848 \\
\hline Prob $>$ Wald Chi2 & 0,0000 & 0,0000 & 0,0000 \\
\hline Observações & 284 & 284 & 284 \\
\hline
\end{tabular}

Estatísticas z corrigidas por painel entre parênteses.

*significativo a $10 \%$; ${ }^{* *}$ significativo a $5 \%$; ${ }^{* * *}$ significativo a $1 \%$. 
Globalização, Política Interna e Gasto Social na América Latina...

Quadro 4

Determinantes dos Gastos com Saúde e Educação em Quatorze Países da América Latina, 1973-1997

\begin{tabular}{|c|c|c|c|}
\hline & D.CAPHUMANO & D.CAPHUMPUBL & D.CAPHUMANPIB \\
\hline L. PIBCAP & $\begin{array}{c}0,02482^{* * *} \\
(5,26)\end{array}$ & $\begin{array}{c}0,00081 \\
(1,59)\end{array}$ & $\begin{array}{c}-0,00007 \\
(0,81)\end{array}$ \\
\hline L. Quebra de Produção & $\begin{array}{c}-0,53871 \\
(0,75)\end{array}$ & $\begin{array}{c}-0,13127 \\
(1,07)\end{array}$ & $\begin{array}{c}-0,00671 \\
(0,27)\end{array}$ \\
\hline L. Dependentes & $\begin{array}{c}-0,32490 \\
(1,63)\end{array}$ & $\begin{array}{c}-0,05597 \\
(1,35)\end{array}$ & $\begin{array}{c}-0,00592 \\
(0,86)\end{array}$ \\
\hline L. Governo & $\begin{array}{c}0,72537^{*} \\
(1,86)\end{array}$ & $\begin{array}{c}-0,04439 \\
(0,52)\end{array}$ & $\begin{array}{c}0,04446^{* * *} \\
(3,13)\end{array}$ \\
\hline D. Governo & $\begin{array}{c}2,74380^{* * *} \\
(4,75)\end{array}$ & $\begin{array}{c}-0,29154^{* *} \\
(2,03)\end{array}$ & $\begin{array}{c}0,09617^{* * *} \\
(5,23)\end{array}$ \\
\hline L. Taxa de Câmbio & $\begin{array}{c}0,00110 \\
(0,44)\end{array}$ & $\begin{array}{c}0,00178 \\
(1,56)\end{array}$ & $\begin{array}{c}0,00003 \\
(0,26)\end{array}$ \\
\hline D. Taxa de Câmbio & $\begin{array}{c}0,00350 \\
(0,67)\end{array}$ & $\begin{array}{c}-0,00085 \\
(0,36)\end{array}$ & $\begin{array}{c}0,00028 \\
(1,03)\end{array}$ \\
\hline L. Comércio & $\begin{array}{c}-0,18819 \\
(1,48)\end{array}$ & $\begin{array}{c}-0,01729 \\
(0,65)\end{array}$ & $\begin{array}{c}-0,00443 \\
(0,96)\end{array}$ \\
\hline D. Comércio & $\begin{array}{c}-0,17520 \\
(1,02)\end{array}$ & $\begin{array}{c}0,00936 \\
(0,25)\end{array}$ & $\begin{array}{c}-0,00533 \\
(0,81)\end{array}$ \\
\hline L. Capital & $\begin{array}{c}-0,05147 \\
(0,50)\end{array}$ & $\begin{array}{c}0,04568^{* *} \\
(2,38)\end{array}$ & $\begin{array}{c}0,00583^{*} \\
(1,85)\end{array}$ \\
\hline D. Capital & $\begin{array}{c}0,26331 \\
(1,35)\end{array}$ & $\begin{array}{c}0,09700^{* * *} \\
(2,62)\end{array}$ & $\begin{array}{c}0,00802 \\
(1,34)\end{array}$ \\
\hline L. Democracia & $\begin{array}{c}7,71009^{* *} \\
(2,02)\end{array}$ & $\begin{array}{c}1,85676^{* *} \\
(2,01)\end{array}$ & $\begin{array}{c}0,22071^{*} \\
(1,77)\end{array}$ \\
\hline D. Democracia & $\begin{array}{c}2,67727 \\
(0,53)\end{array}$ & $\begin{array}{c}2,49207^{*} \\
(1,83)\end{array}$ & $\begin{array}{c}0,01699 \\
(0,10)\end{array}$ \\
\hline L. Popular & $\begin{array}{c}-4,87457 \\
(1,32)\end{array}$ & $\begin{array}{c}-1,40306^{*} \\
(1,68)\end{array}$ & $\begin{array}{c}-0,16366 \\
(1,14)\end{array}$ \\
\hline D. Popular & $\begin{array}{c}-12,89505^{* *} \\
\quad(2,32)\end{array}$ & $\begin{array}{c}-1,75167 \\
(1,58)\end{array}$ & $\begin{array}{c}-0,44433^{* *} \\
\quad(2,18)\end{array}$ \\
\hline Dec-70 & $\begin{array}{c}2,74960 \\
(0,48)\end{array}$ & $\begin{array}{c}1,76608 \\
(1,54)\end{array}$ & $\begin{array}{c}0,15769 \\
(0,76)\end{array}$ \\
\hline Dec-80 & $\begin{array}{c}-4,28160 \\
(1,09)\end{array}$ & $\begin{array}{c}0,97024 \\
(1,20)\end{array}$ & $\begin{array}{c}-0,07972 \\
(0,56)\end{array}$ \\
\hline Var. Dep. Defasada & $\begin{array}{c}-0,50365^{* * *} \\
(6,15)\end{array}$ & $\begin{array}{c}-0,47954^{* * *} \\
(6,03)\end{array}$ & $\begin{array}{c}-0,49991^{* * *} \\
(5,40)\end{array}$ \\
\hline Constante & $\begin{array}{c}-128,27304^{* * *} \\
(3,95)\end{array}$ & $\begin{array}{c}-1,97991 \\
(0,38)\end{array}$ & $\begin{array}{c}0,45990 \\
(0,60)\end{array}$ \\
\hline R-quadrado & 0,4609 & 0,3048 & 0,3961 \\
\hline Prob $>$ Wald Chi2 & 0,0000 & 0,0000 & 0,0000 \\
\hline Observações & 284 & 284 & 284 \\
\hline
\end{tabular}

Estatísticas z corrigidas por painel entre parênteses.

${ }^{*}$ significativo a $10 \%$; ${ }^{* *}$ significativo a $5 \%$; ${ }^{* * *}$ significativo a $1 \%$. 
no modelo geral, opera, primordialmente, através de seus efeitos nas pensões e transferências. As aberturas de comércio têm efeito uniformemente negativo no gasto com seguridade social, tanto a curto como a longo prazos. O coeficiente de abertura de capital é significativo apenas no gasto per capita a longo prazo, mas todos os demais, salvo um, também são negativos. Mais ainda, embora não mostremos os resultados, os efeitos da interação são idênticos àqueles encontrados no modelo geral: a liberalização da conta de capital agrava o efeito do comércio.

Nos modelos dos gastos com saúde e educação (Quadro 4), temos um quadro bastante distinto. De um lado, embora cinco dos seis sinais de comércio continuem negativos, nenhum atinge, sequer, um nível 0,1 de significância. Assim, não podemos rejeitar a hipótese de que o comércio não produz efeitos nessa categoria de gastos. Mais interessante, ainda, é ver que ambos os coeficientes de abertura de capital revelam efeitos positivos e significativos na participação no orçamento, o que pode ser visto como a indicação mais direta das prioridades de gasto do governo. São significativos, também, em relação aos gastos como percentual do PIB a longo prazo. Esses resultados são consideravelmente menos estáveis que os resultados referentes ao comércio em especificações alternativas do modelo, o que aconselha cautela no peso que lhes atribuímos. Ainda assim, eles justificam a defesa da "compensação".

As implicações das variáveis políticas são igualmente interessantes, se não mais. Ao contrário do modelo geral, um número razoável dos coeficientes de democracia e partidarismo é significativo nos Quadros 3 e 4, parecendo realçar a importância das perdas que observamos na troca entre os gastos com seguridade social e com a formação de capital humano.

O Quadro 3 mostra que os governos de base popular têm impacto significativo a curto prazo, em todas as três especificações do modelo. A longo prazo, a prioridade atribuída no orçamento à seguridade social tem, também, maior probabilidade de ser mais alta durante os anos em que governos de base popular estão no poder. Mantendo-se tudo o mais constante, pode-se prever que tais governos elevarão sua participação no orçamento em cerca de 5\%. Conforme argumentamos, tais prioridades de gastos tendem a ser coerentes com as preferências 
Globalização, Política Interna e Gasto Social na América Latina...

das bases sindicais desses líderes e / ou com as inclinações ideológicas dos que apóiam seus partidos.

As democracias, ao contrário, parecem ter um efeito negativo sobre tais programas. Embora o impacto nas dotações orçamentárias seja insignificante, há efeitos estatisticamente significativos no gasto com seguridade social - per capita e como parcela do PIB —, tanto a curto como a longo prazos. Como levantamos inicialmente, a hipótese de que governos eleitos podem responder de forma desproporcional aos eleitores da classe média e da classe dos trabalhadores que apóiam tais programas foi uma surpresa. Temos de acrescentar, ainda, que os resultados - ao contrário do comércio - são sensíveis à especificação do modelo e não atingiram uniformemente os níveis-padrão de relevância quando aplicamos outras técnicas de estimativa. Mesmo assim, os resultados estão alinhados com o que sabemos sobre as características de desigualdade de tais programas e indicam que, no mínimo, as democracias podem cortar gastos sem muita preocupação com reações eleitorais adversas.

Essa especulação recebe apoio adicional quando observamos os resultados dos gastos com saúde e educação mostrados no Quadro 4 . O impacto dos governos de base popular é negativo, desta feita em todas as três especificações de gasto social. Isso sugere que os governos de base popular tendem a apertar os gastos com "capital humano", possivelmente para proteger o gasto com pensões. Por outro lado, as transições para a democracia (D-democracia) levam rapidamente a um aumento nas dotações orçamentárias para capital humano. A longo prazo, os regimes democráticos produzem aumentos de gastos em todas as três especificações do modelo. Os gastos crescem cerca de US\$ 15 per capita (cerca de 7\% da média regional) e 0,45 do PIB (cerca de $18 \%$ da média regional). Os governos democráticos elevam a participação fiscal de saúde e educação em cerca de 4\% (16\% da média regional).

Obviamente, não podemos estar inteiramente seguros dos mecanismos causais por trás desse resultado. Os regimes democráticos podem estar reagindo, também, a pressões dos trabalhadores da área de saúde e dos sindicatos de professores, que tendem a estar entre os componentes mais fortes do trabalho organizado. Alguma pressão pode vir também de capitalistas "esclarecidos", tanto internacionais como locais, interessados em aumentar a qualificação da força de tra- 
Robert R. Kaufman e Alex Segura-Ubiergo

balho. Quando comparamos o impacto da democracia sobre os gastos com capital humano com seu impacto na seguridade social, contudo, fica plausível deduzir que as preferências de uma massa eleitoral também estão agindo.

\section{CONCLUSÕES}

Como a maioria dos estudos estatísticos, nossos resultados deixam várias questões em aberto, muitas das quais somente poderão ser respondidas mediante a utilização de métodos de pesquisa mais qualitativos. Na primeira seção, e em vários outros pontos do trabalho, discutimos diversas explicações para as relações que encontramos entre globalização, pressões políticas e gastos sociais. Em muitos casos, contudo, não podemos afirmar com certeza qual dos vários mecanismos causais, de fato, afeta os resultados. Discutimos esta questão mais detalhadamente no caso dos efeitos, a curto e longo prazos, da liberalização do comércio. Não podemos ter certeza sobre até que ponto os cortes no gasto social agregado e na seguridade social refletem pressões dos produtores, iniciativas dos elementos do governo com poder decisório, ou a indiferença, até oposição, de setores que são excluídos dos benefícios. Questões similares podem ser levantadas, também, sobre outras descobertas, como, por exemplo, os efeitos positivos da abertura de capital sobre os investimentos em saúde e educação, ou a inclinação de governos "de base popular" para reduzir tais gastos.

Para responder a tais questões, precisamos de uma análise mais detalhada da organização dos sistemas de serviços sociais, de quem se beneficiou com eles no passado e de quem tem a ganhar ou perder com eventuais mudanças. Como observamos rapidamente na Introdução, alguns dos desafios mais angustiantes da "segunda fase" das reformas do bem-estar têm menos a ver com o montante do financiamento que com a forma como este é distribuído, e como estão organizados os sistemas de entrega. Geralmente, tais questões são melhor analisadas por intermédio de estudos de casos e comparações entre poucos casos, que permitem exames detalhados das políticas do processo orçamentário e das barganhas em torno do desenho e da implantação dos serviços sociais.

No entanto, ainda que nossa análise não possa revelar definitivamente os mecanismos causais por trás das descobertas estatísticas, 
Globalização, Política Interna e Gasto Social na América Latina...

ela certamente nos dá uma estrutura de referência que pode orientar futuras pesquisas. Três conjuntos de conclusões são de particular importância. O primeiro refere-se às discussões a respeito dos efeitos da integração comercial sobre o Estado de Bem-Estar: a evidência pende irrefutavelmente para a hipótese da eficiência, e não para a de compensação. Embora não estejamos inteiramente seguros sobre por que isto se dá, podemos inferir, de nossos resultados, que a integração comercial de fato altera os recursos de poder, de forma a levar à redução nas pensões e em outras transferências - os componentes do gasto social que mais protegem diretamente contra a vulnerabilidade diante das forças de mercado. Mais ainda, mesmo no caso dos gastos com saúde e educação, não há nenhuma evidência de que a expansão do comércio leve os Estados a aumentar seus compromissos com o bem-estar. Na verdade, se algo pode ser dito é que as aberturas comerciais têm um impacto negativo também nesses componentes do gasto social.

A integração nos mercados globais de capital tem efeitos mais ambíguos. De um lado, parece encorajar aumentos (ou desencorajar reduções) nos gastos com saúde e educação, provavelmente como forma de elevar a qualidade da força de trabalho disponível para os investidores estrangeiros. Mas a liberalização da conta de capital também agrava os efeitos negativos da abertura comercial sobre os gastos com seguridade social. É de se presumir que isto se deva ao aumento do poder de barganha dos produtores de bens comercializados, interessados em conter o custo da mão-de-obra. À medida que as respectivas economias nacionais ficam mais intimamente ligadas aos mercados de capitais, suas ameaças de liquidar seus ativos e transferir-se para outros locais tornam-se mais convincentes.

Uma segunda conclusão significativa é que é importante distinguir os diferentes tipos de gasto social. As distinções usadas aqui seguem aquelas convencionalmente utilizadas nos estudos da Comissão Econômica e Social para América Latina e o Caribe - CEALC, das Nações Unidas. As transferências de seguridade social são, como acabamos de observar, da maior relevância, tanto para a hipótese da eficiência como para a da compensação, porque ambas aumentam as folhas de pagamento e oferecem proteção mais direta contra as forças de mercado. Os gastos com saúde e educação, pode-se argumentar, envolvem investimentos de mais longo prazo em "capital humano" e, 
provavelmente, terão maior impacto a longo prazo sobre a distribuição da renda.

O ponto que fica claramente indicado neste estudo, contudo, é que tais categorias de gasto social são influenciadas por conjuntos bem distintos de fatores políticos e econômicos. A boa nova é que as pronunciadas restrições que a globalização parece impor às transferências de seguridade social não se estendem aos gastos com saúde e educação. Possivelmente, como os setores de saúde e educação abrangem um conjunto mais amplo de interessados, as decisões sobre o gasto nessas áreas parecem refletir uma lógica política distinta, muito mais vinculada à concorrência eleitoral e à participação política. Apesar de os estudos de caso qualitativos das reformas do setor social preocuparem-se mais com a reestruturação que com os gastos, deve-se observar que eles também mostram, consistentemente, distinções entre as políticas das reformas de pensões e os desafios, politicamente mais difíceis, relacionados com a reestruturação dos setores de serviços sociais (ver, p. ex., Nelson, 1997).

Não tentamos explorar as políticas das reformas do setor social neste trabalho. Para manter a clareza da apresentação, também deixamos a análise das diferenças entre os gastos com saúde e os gastos com educação para estudos posteriores. Em decorrência de nossas descobertas até o momento, contudo, uma exploração dessas questões constitui o próximo passo lógico de nossa pesquisa.

Nosso terceiro conjunto de conclusões refere-se à forma como o gasto é afetado por "variáveis políticas" internas. Mostramos que os regimes democráticos e os governos de base popular, efetivamente, têm impactos independentes do impacto da globalização. Tais efeitos, contudo, dependem em grande parte da constelação de interesses afetados pelos diversos tipos de programas sociais, e operam em direções bem distintas.

Como seus correspondentes de "esquerda" na Europa Ocidental, os governos de base popular da América Latina são uma força importante na proteção ou ampliação dos programas de transferência de bem-estar. Na Europa Ocidental, contudo, os programas voltados para a grande classe trabalhadora sindicalizada, geralmente, contribuem para uma redução da desigualdade, enquanto nos mercados de trabalho segmentados da América Latina os benefícios para os traba- 
Globalização, Política Interna e Gasto Social na América Latina...

lhadores do setor formal podem reforçar a distância entre eles e os trabalhadores do campo e do setor informal. Talvez esta seja a razão pela qual vemos a "democracia" trabalhando sistematicamente para reduzir a categoria de seguridade social.

Em oposição às descobertas de Brown e Hunter (1999), não descobrimos nenhum forte impacto da democracia nos níveis gerais de gasto, mas isso se deve apenas ao fato de que essa medida agrega programas com efeitos sociais bem diferentes. Em concordância com seu argumento de que "o regime importa", os governos democraticamente eleitos, de fato, protegem os gastos com saúde e educação. Ainda que exames mais matizados do desenho constitucional e dos esquemas institucionais possam, sem dúvida, nos revelar mais sobre tais efeitos, nossas descobertas sugerem que as democracias latino-americanas, em geral, apóiam as demandas por formas mais "progressivas" de gasto social.

(Recebido para publicação em junho de 2001)

\section{NOTAS}

1. Por não haver dados, ou por não serem comparáveis aos disponíveis, não pudemos incluir Colômbia, Cuba, Haiti, Honduras, Nicarágua e Panamá.

2. O impacto distributivo do gasto social ainda é objeto de debate empírico. Um importante estudo realizado sob os auspícios da Comissão Econômica e Social para América Latina e o Caribe - CEALC, das Nações Unidas revela que o gasto social tem um impacto positivo sobre o quintil mais baixo na Argentina, no Brasil, no Chile e na Colômbia (Mostajo, 2000).

3. Garrett (1999) utiliza os gastos gerais de consumo do governo, mas isso se baseia em médias de cortes transversais e não inclui transferências.

4. Tentamos, também, outras especificações para democracia, com (1) utilização de uma medida contínua, ou (2) alteração do ponto de corte de 6 para 7 ou 5 . Não verificamos nenhuma alteração significativa nos resultados.

5. Rodamos, também, regressões substituindo anos simulados por décadas simuladas. Isto não afetou significativamente os resultados.

6. Por não terem dado atenção a esses problemas técnicos, alguns estudos anteriores tiveram seus resultados questionados. Por exemplo, em uma réplica do influente estudo de Hicks e Swank (1992) sobre o gasto na OCDE, apenas 4 das 13 variáveis 


\section{Robert R. Kaufman e Alex Segura-Ubiergo}

políticas e institucionais atingem níveis convencionais de relevância quando são usados erros-padrão corrigidos por painéis (Beck e Katz, 1995).

7. Esse modelo é equivalente ao que foi descrito por Beck e Katz (1995), no qual os autores explicam a importância de se separar os efeitos de curto prazo dos de longo em modelos dinâmicos (ver Apêndice Técnico).

8. Em todas os quadros, as variáveis precedidas de "L" são medidas em níveis; as variáveis precedidas de " $\mathrm{D}$ " são medidas em primeiras diferenças (na maioria dos casos, as primeiras diferenças das três primeiras variáveis de controle não foram significativas e, por isso, não são mostradas). Estimativa com um modelo de correção que é robusto para unidades de raízes (ver Apêndice Técnico). O teste do multiplicador Lagrange indica que o modelo não é afetado por correlação serial. Modelo estimado com efeitos fixos (modelo de variáveis simuladas de mínimos quadrados). Os países simulados não estão indicados por razão de espaço. O país simulado para a Argentina foi omitido para evitar a colinearidade perfeita. Um teste F para verificar a significância dos efeitos fixos indicou que, a um nível de $5 \%$ (ou melhor), os efeitos fixos pertencem ao modelo. A correlação entre os efeitos fixos e as variáveis explicativas é cerca de 0,8 . Assim, o modelo não pode ser estimado com efeitos randômicos. O modelo foi estimado com o comando "xtpcse" no STATA 7.0. Técnicas alternativas de estimativa como "rreg" (regressão robusta), probabilidade máxima, método de momentos generalizados ou o estimador Arellano-Bond não produziram alterações significativas em nossos principais resultados. Assim, preferimos usar os MQOs com erros corrigidos por painel, conforme sugestão de Beck e Katz (1995), devido à sua relativa simplicidade e à facilidade de interpretação dos resultados.

9. Uma série seqüencial de regressões onde um país foi excluído de cada vez indica que esses resultados não são causados por nenhum país determinado. Para verificar possíveis fatores externos, utilizamos regressões robustas que usaram distâncias D-beta e Cook para corrigir desvios incomuns observados, e obtivemos resultados bastante similares.

10. Ver no Apêndice Técnico a fórmula aplicada nesses cálculos.

11. Quinn (1997) também encontra uma relação positiva em seu estudo dos países da OCDE, assim como Garrett (1999) em sua amostra global.

12. Observe que no modelo da interação os coeficientes individuais para comércio e capital são necessários como controle, mas não têm significado material. O coeficiente de cada variável que não tenha interagido mede seu impacto quando o valor da outra variável for zero (ver Friedrich, 1982).

13. Somos gratos a William Roberts Clark, do Departamento de Ciência Política da New York University, por seu aconselhamento metodológico e sua assistência nesta parte do trabalho. 
Globalização, Política Interna e Gasto Social na América Latina...

\section{REFERÊNCIAS BIBLIOGRÁFICAS}

ÁLVAREZ, Michael, CHEIBUB, José Antonio, LIMONGI, Fernando e PRZEWORSKI, Adam. (1996), "Classifying Political Regimes". Studies in Comparative International Development, vol. 31 .

AVELINO, George Filho. (2000), Economic Crisis, Democratization, and Social Expenditure in Latin America, 1980-1994. Tese de Doutorado, Stanford University.

BANERJEE, Anindya, DOLADO, Juan, GALBRAITH, John e HENRY, David. (1993), Co-Integration, Error Correction, and the Econometric Analysis of Non-Stationary Data. Oxford, Oxford University Press.

BECK, Nathaniel e KATZ, Jonathan. (1995), "What to Do (and Not to Do) with Time-Series Cross-Section Data". American Political Science Review, vol. 89, ํㅡ 3 .

_. (1996), "Nuisance versus Substance: Specifying and Estimating Time-Series Cross-Section Models". Political Analysis, no 6.

BROWN, David e HUNTER, Wendy. (1999), “Democracy and Social Spending in Latin America, 1980-92". American Political Science Review, vol. 93.

CAMERON, David. (1978), "The Expansion of the Public Economy: A Comparative Analysis". American Political Science Review, vol. 72, nํ⒋

ECLAC - Economic and Social Comission on Latin America and the Caribbean. (1999), Social Panorama of Latin America.

ESPING-ANDERSEN, Gosta. (1990), The Three Worlds of Welfare Capitalism. Princeton, Princeton University Press.

_. (1999), Welfare States in Transition: National Adaptations in Global Economies. London, Sage Publications.

FMI — Fundo Monetário Internacional. (vários anos), Government Finance Statistics.

FRIEDEN, Jeffry. (1991), Debt, Development, and Democracy. Princeton, Princeton University Press.

FRIEDRICH, Robert. (1982), “In Defense of Multiplicative Terms”. American Journal of Political Science, vol. 26.

GARRETT, Geoffrey. (1999), Globalization and Government Spending around the World. Trabalho apresentado na Reunião Anual da American Political Science Association - APSA, 1-5 de setembro.

GREENE, William. (2000), Econometric Analysis (4⿳亠丷厂 ed.). New Jersey, Prentice Hall, pp. 733-735.

HAGGARD, Stephan e KAUFMAN, Robert R. (1995), The Political Economy of Democratic Transitions. Princeton, Princeton University Press.

HICKS, Alexander. (1999), Social Democracy and Welfare Capitalism: A Century of Income Security Politics. Ithaca, Cornell University Press.

_eSWANK, Dwane. (1992), "Politics, Institutions and Welfare Spending in Industrialized Democracies, 1960-1982". American Political Science Review, vol. 86, nº 3. 


\section{Robert R. Kaufman e Alex Segura-Ubiergo}

HUBER, Evelyne. (1996), “Options for Social Policy in Latin America: Neoliberal versus Social Democratic Models", in G. Esping-Andersen (ed.), Welfare States in Transition: National Adaptations in Global Economies. London, Sage Publications.

_ e STEPHENS, John. (2001), Development and Crisis of the Welfare State: Parties and Policies in Global Markets. Chicago, University of Chicago Press.

IVERSSEN, Torben e CUSACK, Thomas. (2000), "The Causes of Welfare State Expansion: Deindustrialization or Globalization?". World Politics, vol. 52, no 3 .

JAGGERS, Keith e GURR, Ted Robert. (1996), Polity III: Regime Type and Political Authority, 1800-1994 (arquivo eletrônico). Maryland, University of Maryland.

KATZENSTEIN, Peter. (1985), Small States in World Markets. Ithaca, Cornell University Press.

KRUGMAN, Paul. (1999), International Economics. New York, Addison-Wesley Longman.

MESA-LAGO, Carmelo. (1978), Social Security in Latin America: Pressure Groups, Stratification, and Inequality. Pittsburgh, University of Pittsburgh Press.

_. (1989), Ascent to Bankruptcy: Financing Social Security in Latin America. Pittsburgh, Pittsburgh University Press.

MORLEY, Samuel, MACHADO, Roberto e PETTINATO, Stefano. (1999), “Indexes of Structural Reform in Latin America". Santiago, ECLAC - Economic Development Division, LC/L.1166.

MOSTAJO, Rossana. (2000), “Gasto Social y Distribución del Ingreso: Caracterización y Impacto Redistributivo en Paises Seleccionados de América Latina y el Caribe". Serie Reformas Económicas, nº 69, Santiago, ECLAC.

NELSON, Joan M. (1997), "Social Costs, Social-Sector Reforms, and Politics in PostCommunist Transformations", in J. M. Nelson, C. Tilly e L. Walker (eds.), Transforming Post-Communist Political Economies. Washington, D.C., National Academy Press.

_. (2000), "The Politics of Pension and Health-Care Delivery: Reforms in Hungary and Poland", in J. Kornai, S. Haggard e R. R. Kaufman (eds.), Reforming the State: Fiscal and Welfare Reform in Post-Socialist Countries. New York, Cambridge University Press.

PIERSON, Paul. (1996), “The New Politics of the Welfare State”. World Politics, vol. 48, no 3.

QUINN, Dennis. (1997), “The Correlates of Change in International Financial Regulation". American Political Science Review, vol. 91, ํo 3 .

RODRIK, Dani. (1997), Has Globalization Gone Too Far? Washington, D.C., Institute for International Economics.

ROGOWSKI, Ronald. (1989), Commerce and Coalitions. Princeton, Princeton University Press.

RUDRA, Nita. (no prelo), "Globalization and the Decline of the Welfare State in Less Developed Countries". International Organization. 
Globalização, Política Interna e Gasto Social na América Latina...

SAYRS, Lois. (1989), Pooled Time Series Analysis. London, Sage Publications.

STALLINGS, Barbara e PERES, Wilson. (2000), Growth, Employment and Equity: The Impact of Economic Reform in Latin America and the Caribbean. Washington, D.C., Brookings Institution Press.

WDI — World Development Indicators. (2000), Banco Mundial. 
Robert R. Kaufman e Alex Segura-Ubiergo

\section{APÊNDICE TÉCNICO}

O modelo de correção de erro é dado por:

$$
\Delta \mathrm{Y}_{\mathrm{i}, \mathrm{t}}=\alpha+\Delta \mathrm{X}_{\mathrm{i}, \mathrm{t}-1} \beta_{\mathrm{k}}+\phi\left(\mathrm{Y}_{\mathrm{i}, \mathrm{t}-1}-\mathrm{X}_{\mathrm{i}, \mathrm{t}-\mathrm{Y}} \mathrm{Y}\right)+\epsilon_{\mathrm{i}, \mathrm{t}}(1),
$$

onde, em nosso caso, $\mathrm{Y}_{\mathrm{i}, \mathrm{t}}$ representa os gastos sociais no país $i$ durante o ano $t, \Delta$ é o operador das primeiras diferenças, $X$ é um vetor de variáveis independentes, e $\epsilon_{i, t}$ é um termo de intensidade igual em todas as freqüências. $\mathrm{O}$ modelo descreve uma relação de equilíbrio a curto prazo dada por $\Delta Y_{i, t}=\alpha+\Delta X_{i, t-1} \beta_{k}+\epsilon_{i, t}$ e um termo $\phi\left(Y_{i, t-1}-X_{i, t-1} Y\right)$, que mede o desvio dessa relação de equilíbrio a curto prazo [Note que, $\left.\epsilon_{i, t-1}=\left(Y_{i, t-1}-X_{i, t-1} Y\right)\right]$. A equação (1) mostra que, primeiro, uma mudança em $X_{i, t-1}$ que ocorra apenas uma vez produzirá uma mudança contemporânea em $\mathrm{Y}_{\mathrm{i}, \mathrm{t}}$. Esse efeito a curto prazo é determinado pelo vetor dimensional da variável explicativa $\beta_{\mathrm{k}}$. Além disso, quando o impacto de $X_{i, t-1}$ sobre $Y_{i, t}$ afasta o modelo de seu equilíbrio a longo prazo (dado pelo vetor de co-integração $Y^{*}{ }_{i, t-1}=X^{*}{ }_{i, t-1} Y$, onde 0 "** indica equilíbrio), a discrepância ou "erro" $\left(\mathrm{Y}_{\mathrm{i}, \mathrm{t}-1}-\mathrm{X}_{\mathrm{i}, \mathrm{t}-\mathrm{1}} \mathrm{Y}\right)$ é corrigida à taxa anual $\phi$.

Uma forma de mostrar mais intuitivamente como se interpretam os coeficientes a curto e longo prazos é transformar a equação (1) usando uma operação matemática simples: define-se $\beta_{j} \operatorname{como}-(\phi Y)$, onde ambos os parâmetros $\phi$ e Y provêm da equação 1 , o que leva a $Y=\beta_{j} /-\phi$. A equação 1 poderá então ser reescrita da seguinte forma:

$$
\Delta Y_{i, t}=\alpha+Y_{i, t-1} \phi+\Delta X_{i, t-1} \beta_{k}+X_{i, t-1} \cdot \beta_{j}+\epsilon_{i, t}(2)
$$

A equação 2 é estimada pelos Mínimos Quadrados Ordinários. A interpretação dos coeficientes, então, será: o coeficiente de regressão para uma variável de nível é uma medida do equilíbrio a longo prazo entre um vetor de variáveis independentes co-integradas (isto é, que têm a mesma tendência a longo prazo) e da variável dependente. Como já foi observado acima, a relação de equilíbrio a longo prazo é dada por $\mathrm{Y}^{*}{ }_{\mathrm{i}, \mathrm{t}-1}=\mathrm{X}_{\mathrm{i}, \mathrm{t}-\mathrm{1}} \mathrm{Y}$. O parâmetro $\mathrm{Y}$ (que mede o equilíbrio dessa relação a longo prazo) não é diretamente observável pela equação (2), mas pode ser encontrado dividindo-se $\beta_{\mathrm{j}}$ por $-\phi$ (ver acima).

Por outro lado, a importância dos efeitos de $\Delta \mathrm{X}_{\mathrm{i}, \mathrm{t}-1}$ a curto prazo depende da dimensão de $\beta_{\mathrm{k}}$ e do tempo durante o qual persistirão os efeitos das mudanças em $X_{i, t-1}$. Uma mudança em $X_{i, t-1}$, que ocorra ape- 
Globalização, Política Interna e Gasto Social na América Latina...

nas uma vez, produzirá uma mudança imediata (contemporânea) em $Y_{i, t}$ que é medida por $\beta_{k}$. Se, em qualquer tempo thouver uma mudança em $X_{i, t}$ em sentido oposto ao da mudança em $X_{i, t-1}$, não haverá nenhum outro efeito. Mas, se a mudança em $X_{i, t-1}$ for sustentada, então o impacto continuará em períodos subseqüentes e poderá ser medido por $\Delta \mathrm{X}_{\mathrm{i}, t-1} .(1+\phi)^{\mathrm{t}}$, onde té o número de períodos posteriores à mudança inicial. Assim, por exemplo, três anos após a mudança inicial $\Delta \mathrm{X}_{\mathrm{i}, \mathrm{t}-1}$, o efeito será $\Delta \mathrm{X}_{\mathrm{i}, \mathrm{t}-1}(1+\phi)^{3}$. Como $0<\phi<-1$, quanto menor for o valor de $\phi$, maior o tempo de sustentação das mudanças em $X$. 
Robert R. Kaufman e Alex Segura-Ubiergo

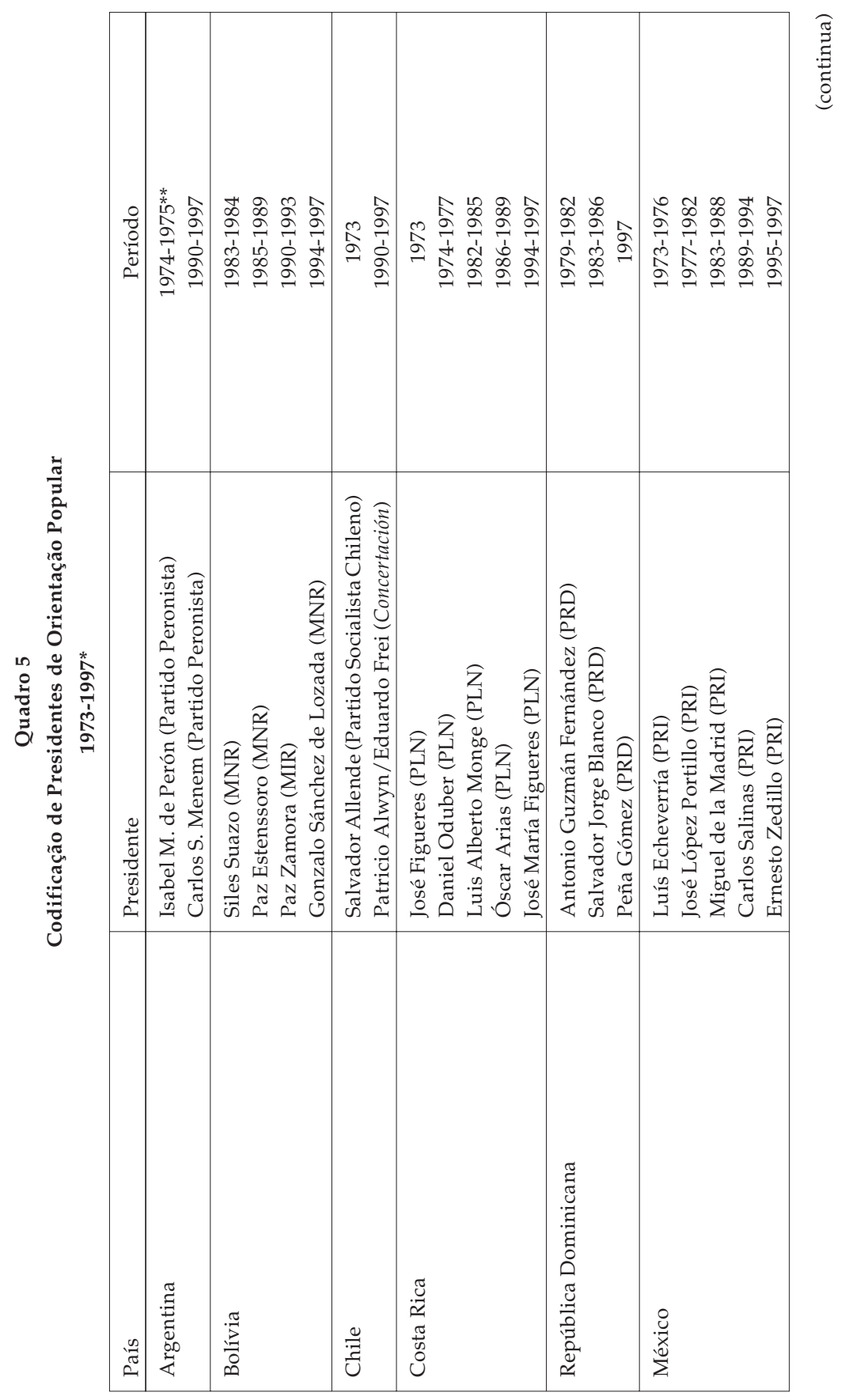


Globalização, Política Interna e Gasto Social na América Latina...

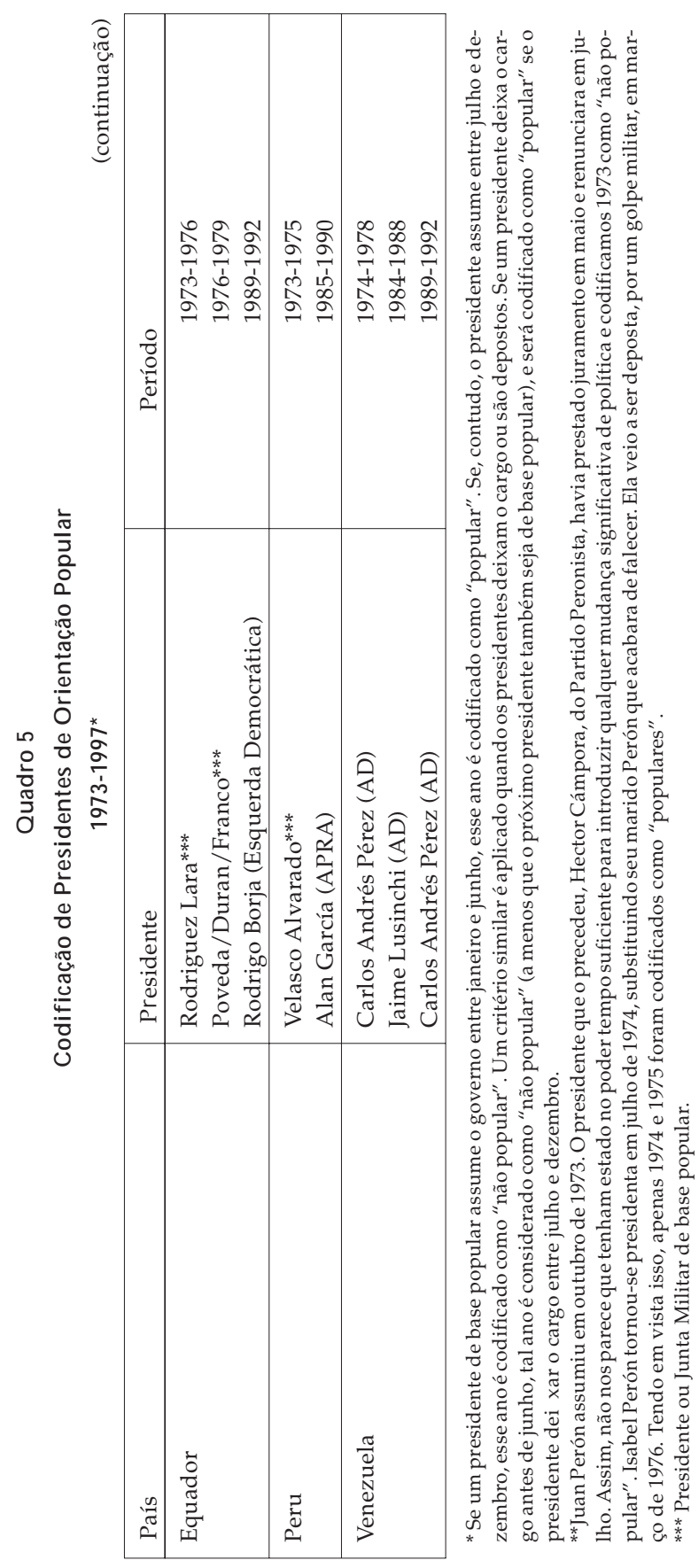


Robert R. Kaufman e Alex Segura-Ubiergo

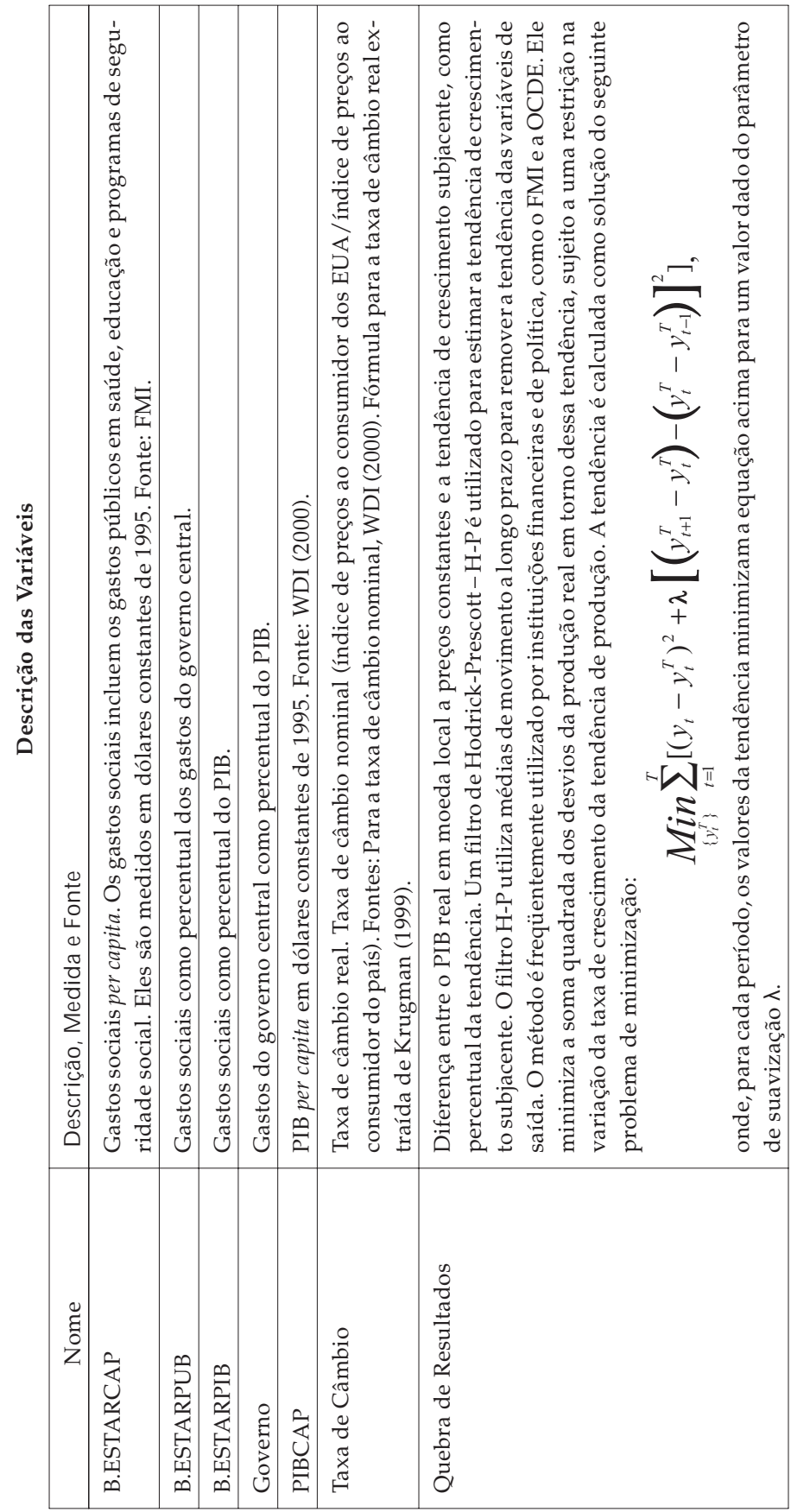

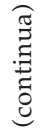


Globalização, Política Interna e Gasto Social na América Latina...
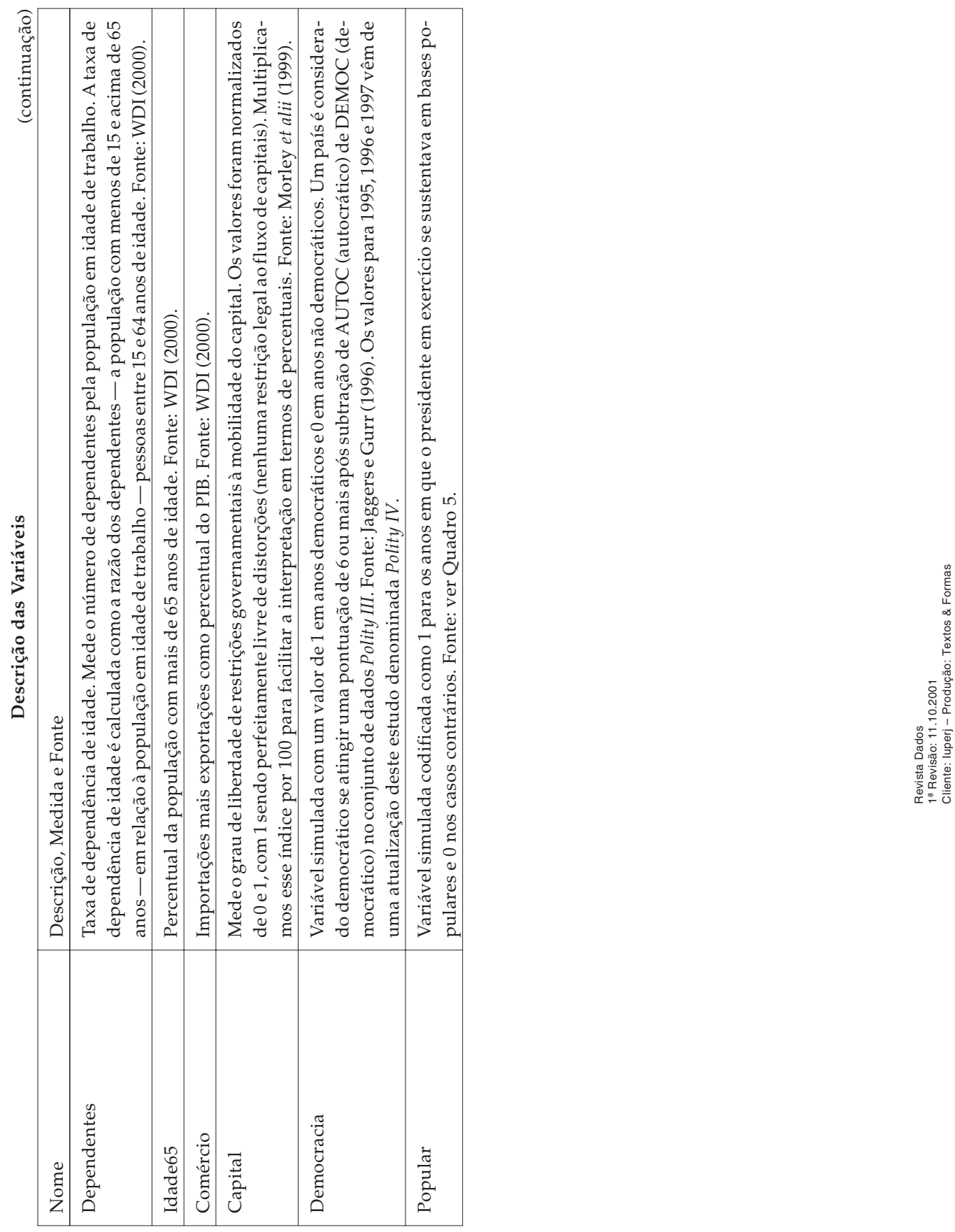
Robert R. Kaufman e Alex Segura-Ubiergo

\author{
ABSTRACT \\ Globalization, Domestic Politics and Social Spending in Latin America: \\ A Time-Series Cross-Section Analysis, 1973-1997
}

This study examines the effects of globalization, democratization, and partisanship on social spending in 14 Latin American countries from 1973 to 1997, using a pooled time-series error-correction model. We examine three sets of issues. First, following debates in the literature on OECD countries, we want to know whether social spending has been encouraged or constrained by integration into global markets. Within this context, we examine the extent to which such outcomes might be influenced by two additional sets of domestic political and institutional factors discussed in work on developed countries: the electoral pressures of democratic institutions, and whether or not popularly-based governments are in power. We show that trade integration has a consistently negative effect on aggregate social spending, and that this is compounded by openness to capital markets. This is the strongest and most robust finding in our study. Neither democratic nor popularly-based governments consistently affect overall social spending. We then disaggregate spending into social security transfers and expenditures health and education. We find that popularly-based governments tend to protect social security transfers, which tend to flow disproportionately to their unionized constituencies, but have a negative impact on health and education spending. Conversely, the change to democracy leads to increases in health and education spending, which reaches a larger segment of the population. We conclude by emphasizing the contrasting political logics of the different types of social spending.

Key words: Latin America; globalization; social spending

\title{
RÉSUMÉ
}

Globalisation, Politique Intérieure et Dépense Sociale en Amérique Latine: Analyse Transversale d'une Série Temporelle, 1973-1997

Cette étude analyse les effets de la globalisation, de la démocratisation et de la nouvelle donne politique sur les dépenses sociales dans 14 pays de l'Amérique Latine de 1973 à 1997. Nous y examinons trois types de réponses. D'abord, suivant les discussions au sein des pays de l'OCDE, nous cherchons à savoir si les investissements sociaux ont été encouragés ou contraints par l'intégration de ces pays dans les marchés globaux. Dans ce contexte, nous étudions jusqu'à quel point ces conséquences pouvaient être influencées par deux autres ensembles de facteurs internes (politiques et institutionnels) 
Globalização, Política Interna e Gasto Social na América Latina...

agissant dans des pays développés: les pressions électorales des institutions démocratiques et si les gouvernements au pouvoir avaient-ils, oui ou non, une base populaire. Nous démontrons que l'intégration commerciale a eu un effet assez négatif sur l'agrégat de dépenses sociales que l'ouverture à des marchés de capital ne fait que renforcer. La conclusion la plus importante de notre étude étant donc que la variable gouvernement démocratique $X$ gouvernement populaire n'affecte pas le montant de l'investissement social. Nous avons donc désagréger les investissement en sécurité social des Etats de leurs budgets santé et éducation. L'analyse a ainsi révélé la tendance des gouvernements populaires à protéger les transferts de capitaux vers la sécurité sociale, quand même son partage entre les personnes cotisant serait inéquitable et son impact sur les dépenses avec la santé et l'éducation des populations négatif. En revanche, dans certains pays, le processus de démocratisation a entraîné un accroissement de la dépense avec la santé et l'éducation de leurs citoyens, ce qui a bénéficié un segment plus large de la population. Nous soulignons donc les logiques contrastées de ces différents types de dépense sociale.

Mots clés: Amérique Latine; globalisation; dépense sociale 